\title{
Modeling of Magnetorheological Dampers under Various Impact Loads
}

\author{
K. Sarp Arsava and Yeesock Kim \\ Department of Civil and Environmental Engineering, Worcester Polytechnic Institute (WPI), Worcester, MA 01609-2280, USA \\ Correspondence should be addressed to Yeesock Kim; yeesock@wpi.edu
}

Received 16 October 2014; Revised 22 December 2014; Accepted 5 January 2015

Academic Editor: Nuno M. Maia

Copyright (C) 2015 K. S. Arsava and Y. Kim. This is an open access article distributed under the Creative Commons Attribution License, which permits unrestricted use, distribution, and reproduction in any medium, provided the original work is properly cited.

\begin{abstract}
Magnetorheological (MR) damper has received great attention from structural control engineering because it provides the best features of both passive and active control systems. However, many studies on the application of MR dampers to large civil structures have tended to center on the modeling of MR dampers under seismic excitations, while, to date, there has been minimal research regarding the MR damper model under impact loads. Hence, this paper investigates nonlinear models of MR dampers under a variety of impact loads and control signals. Two fuzzy models are proposed for modeling the nonlinear impact behavior of MR dampers. They are compared with mechanical models, the Bingham and Bouc-Wen models. Experimental studies are performed to generate sets of input and output data for training, validating, and testing the models: the deflection, acceleration, velocity, and current signals. It is demonstrated that the proposed fuzzy models are effective in predicting the complex nonlinear behavior of the MR damper subjected to a variety of impact loads and control signals. The proposed fuzzy model resulted in an accuracy of $99 \%$ to predict the impact forces of the MR damper.
\end{abstract}

\section{Introduction}

1.1. Collision Load. In recent years, the threat of impact or explosive loads has become an important topic to be taken into account in the design of structures [1-7]. The impact and impulsive loads due to accidents, collisions, and terrorist or military conditions can threaten the integrity of structures (Figure 1). For instance, the nonlinear material behaviors and high velocity responses, which are not considered in most of the existing structural design methods, can cause severe damage to the structural components. The partial or complete collapse of load bearing elements and shifting or unseating failures of upper parts in structures are the most common failure mechanisms due to such impact loadings. To address such issues, structural control systems have been proposed as smart impact energy absorbers [8]. However, it is quite challenging to develop an effective structural control algorithm due to the complicated nonlinear behavior of the integrated systems and the uncertainties of high impact forces.
1.2. Impact Response Mitigation: Structural Controls. A control system can be implemented into a structure to adjust the stiffness or damping of the structure [9-12]. Such control systems can be categorized into three main groups: passive, active, and semiactive systems [13-16]. Due to their low cost and relative easy design, passive dampers are the most widely used devices for structural control system design in the field of civil structures [10]. Passive control systems do not require any external power source to operate the control device to damp the responses of excited structures. However, the effectiveness of the passive control systems is dependent on the design spectra of destructive environmental forces since they do not have the capability of a feedback-based parameter updating [17]. On the other hand, active control systems adjust the force levels of the mechanical devices within the structure based on the structural response feedback [9]. However, active controllers are highly dependent on a large external power suppliers to operate large actuators $[18,19]$. If there is an electricity cut or some of the control feedback components such as wires and sensors are damaged, 


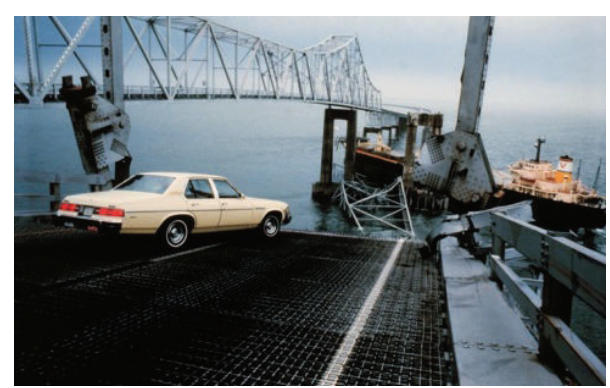

Figure 1: Vessel-bridge collision.

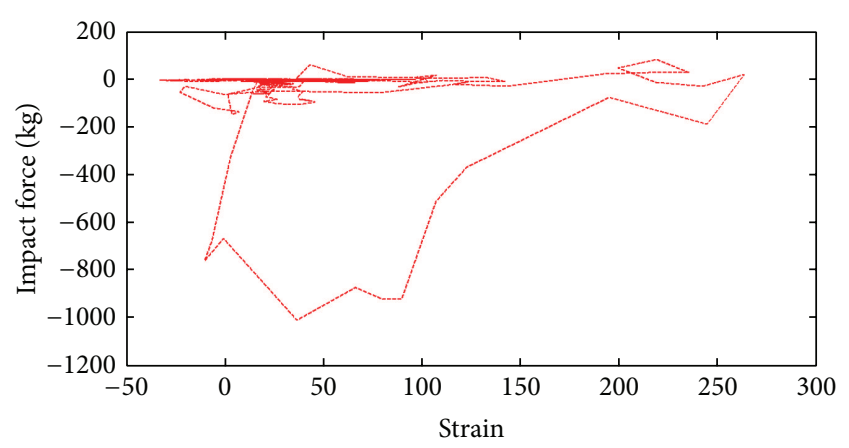

FIGURE 2: Nonlinear behavior of an MR damper under high impact loads.

a malfunction of the active controllers may occur [20, 21]. To address such issues, a solution could be found in semiactive control systems, which combines the good features of both passive and active control systems. Semiactive controller adjusts the level of control forces of smart control devices within structural systems in real time without requiring large power sources $[7,22]$.

1.3. MR Damper Modeling. As a smart controller, magnetorheological (MR) damper has received great attention from various fields of engineering $[13,23]$ due to the favorable features such as fast response time, reliable operation, and low manufacturing cost [15, 24-29]. MR damper is a viscous liquid damper that consists of small magnetically polarized particles whose flow rate can be adjusted according to the strength of the applied magnetic field [30]. To fully use the MR damper technology in implementing into high impact resistant infrastructural systems, a robust computational model that can describe the complex nonlinear behavior of the MR damper first needs to be developed.

One of the biggest challenges in semiactive control system design is the development of an accurate mathematical model of the MR damper system due to the highly nonlinear behavior of MR damping device [31-35]. Moreover, the nonlinear behavior becomes more complex when the MR damper is excited by unexpected high impact loads. Figure 2 depicts the nonlinear relationship between the high impact forces and the corresponding strains, which is one of the parameters that affect the highly nonlinear hysteretic behavior of the MR damper. Note that the strain is a dimensionless quantity; that is, it has no units. When a variety of impact forces and various control current signals are considered, the complex behavior will be much more complicated. Hence, it would be very challenging to develop an idealized parametric mechanical model for an MR damper under a variety of impact forces and control current control signals.

1.4. System Identification. Such a challenging issue on the complex modeling can be addressed by applying nonlinear system identification (SI) methodologies [36]. SI methodologies can be categorized into two parts: parametric and nonparametric [31, 37-39]. The parametric approach uses the physical quantities of systems while the nonparametric SI method trains the input-output map of the system to define the architecture of the mathematical model [32, 4042]. There exist few studies that performed the parametric system identification of MR dampers subjected to high impact loads [3, 43, 44]. Xiang et al. [44] presented a parametric study to predict the shock isolation performance of MR dampers under impact loads. A RD-1005-3-type MR damper was tested under impact loads at different constant current signals. The results demonstrated that the area of the hysteric response curves has a highly nonlinear relationship with the current that is applied to the MR damper. Thus, instead of using a typical Bouc-Wen model, they proposed a modified Bouc-Wen model to predict the nonlinear behavior of MR dampers under impact loads. It was demonstrated that the modified Bouc-Wen model has a good performance in predicting the impact response of MR dampers [44]. However, the model was not tested under a variety of current signals; that is, not random but constant current signals were investigated. Lee et al. [43] used the Herschel-Bulkley shear model, which is a modified version of Bingham model, to evaluate the performance of ER-MR impact damper systems. The equation of motion of the impact dampers was derived and its computer simulations were performed to analytically evaluate the characteristics of the ER-MR impact damper system under impact loads with constant current signals. The effects of flow behavior index on the performance of the impact damper system were evaluated. However, they investigated the MR damper performance under a single impact scenario using constant current signals.

As previously discussed, all of the aforementioned approaches have focused on the application of parametric models to the impact force estimation of MR dampers under constant current and limited impact scenarios. It is very challenging to develop a robust model for impact force prediction of an MR damper under a variety of applied current signals and impact scenarios. Note that the relationship between the collision forces and the associated MR damping forces is highly nonlinear. The nonlinear relationship between the applied current and the MR damper under impact loads makes the modeling process much more difficult. With this in mind, a nonparametric approach, fuzzy models are proposed for the development of an MR damper model under a variety of impact scenarios and random current signals. The reason is that the fuzzy model is effective in modeling the complex nonlinear behavior of dynamic systems with parameter uncertainties. 
1.5. Neurofuzzy Modeling. The neurofuzzy approaches have been commonly applied to civil engineering problems [35, 37, 40, 45-50]. Muzzammil [51] proposed an adaptive neurofuzzy inference system (ANFIS) to predict the maximum possible scour depth for bridge abutments. In the study, a regression model (RM) and artificial neural networks (ANNs) were used as baselines. It was demonstrated that the ANFIS model in predicting the scour depth outperforms other models. Na et al. [52] used the ANFIS to predict the compressive strength of concrete systems. The mix proportions and the results of nondestructive tests such as ultrasonic pulse velocity and rebound hammer test were used as inputs. Four different models were assessed using different inputs. The results showed that the ANFIS model can be reliably used to predict the compressive strengths of concretes without performing costly experimental investigation. Balasubramaniam et al. [53] investigated the characteristics of glass fiber strengthened reinforced concrete beams due to corrosion damage. An experimental study was performed including 21 specimens with and without corrosion damage. The percentage of corrosion, the type of fiber reinforced polymer (FRP) laminate, and the thickness of the FRP plate were used as inputs in the ANFIS model to predict the load bearing, cracking, and ductility behaviors of the concrete system. It was shown that the ANFIS is very effective in predicting the defined outputs for the given system.

Because of their proven usefulness to estimate incomplete and incoherent measurements, the use of neurofuzzy models to identify the behavior of MR dampers has attracted a great deal of attention $[30,54,55]$. Schurter and Roschke [30] proposed the use of the ANFIS to describe the behavior of the SD-1000 MR damper subjected to sine, step, triangle, and pseudorandom signals. Data for training and validating the ANFIS were obtained from the mathematical model of the MR damper proposed by Spencer et al. [13]. Displacement, velocity, and voltage were used as inputs to predict the MR damping force. Various constant voltage signals in the range of $0-3 \mathrm{~V}$ was used in the experiments. The results showed that the proposed ANFIS model successfully represented the behavior of the MR damper. Another application was performed by Wang and $\mathrm{Hu}$ [56]. They proposed a novel way to describe the direct and inverse model of the MR damper. The direct and inverse ANFIS models were developed for the identification of the MR damper subjected to sinusoidal loading. In the training of the direct ANFIS model, the relative velocity, relative acceleration, and the control current were used as inputs while the MR damping force was an output. As an inverse model of an MR damper, the MR damping forces, the relative velocity, and the relative acceleration were used as input signals to predict the applied current. The numerical simulation demonstrated that the ANFIS systems can precisely model the direct and inverse problems of the MR damper under sinusoidal loading. Zeinali et al. [57] proposed the use of the ANFIS modeling approach for modeling of two MR dampers (long- and short-stroke dampers). The MR dampers employing constant current signals ( $0-1 \mathrm{~A})$ were tested under low frequency loads $(1.9 \mathrm{~Hz}-12.6 \mathrm{~Hz})$. Current signal, displacement, and velocity data obtained from the experimental study were used as inputs to predict the MR damping force. It was demonstrated that the proposed ANFIS models successfully predict the behaviors of MR dampers.

Although all of the aforementioned approaches have successfully modeled the behavior of the MR damper under low frequency excitations, the modeling of the MR damping forces under a variety of impact scenarios and random control currents still remains far from being fully answered. With this in mind, this paper focuses on the neurofuzzy system identification of an MR damper itself subjected to a variety of high impact loads and random current signals. It should be noted that a dynamic load can be designated as an impact load if the magnitude is over 0.2 tons with an average of $0.5 \mathrm{~ms}$ peak force duration $[58,59]$. It is indicated that the frequency of collision loads such as barge impact force can reach up to $50 \mathrm{~Hz}[60,61]$. Thus, the capture of the rapid and nonlinear changes in the system responses may be challenging for conventional models. In this context, a new experimental setup and a variety of numerical models are investigated for modeling the complex impact behavior of an MR damper, including a neurofuzzy, a modified neurofuzzy, a modified Bingham, and a modified Bouc-Wen models.

This paper is organized as follows. Section 2 discusses both parametric SI (Bouc-Wen and Bingham) as well as nonparametric (neurofuzzy models) approaches. The experimental setup and its procedures are described in Section 3. In Section 4, the results of the models including training, validation, and testing are presented. Concluding remarks are given in Section 5.

\section{System Identification}

As baselines, the Bouc-Wen model and the Bingham model are described in brief and then the neurofuzzy models are discussed.

2.1. Bouc-Wen Model. A Bouc-Wen model has been commonly accepted in the field of MR damper technology [13, $44,62]$. The restoring force of the MR damper is described as follows:

$$
f_{\mathrm{MR}}=C_{0} \dot{u}+K_{0} u+\alpha_{0} z,
$$

where the evolutionary variable $z$ is described by the firstorder differential equation

$$
\dot{z}=-\gamma|\dot{u}| z|z|^{n a-1}-\beta \dot{u}|z|^{n a}+Q \dot{u},
$$

where $f_{\mathrm{MR}}, \dot{u}$, and $u$ are the damping force, velocity, and deflection of the piston rod, respectively. $C_{0}$ is the damping coefficient, $K_{0}$ is the elastic coefficient, and $\alpha_{0}, \gamma, \beta$, na, and $Q$ are shape parameters related to current signals. Although the Bouc-Wen model has been extensively used for modeling the hysteretic behavior of dynamic systems, it is very challenging to optimize its characteristic parameters. It may be hard to generalize the characteristic parameters for different excitations. The reason is that the parameters of traditional Bouc-Wen models are not functions of the frequency, amplitude, and current signal [63]. The estimated parameters would need to be reestimated, which is a hard and computationally expensive process, when it is expected 
that the MR damper is excited by different excitations. In this context, Dominguez et al. [64] proposed a new methodology to determine the constant parameters of the Bouc-Wen model. The following relationships were proposed:

$$
\begin{gathered}
f_{\mathrm{MR}}=\left(d_{1} \omega^{d_{2}}\right)\left(d_{3} u_{\max }^{d_{4}}\right)\left[C_{0}(I) \dot{u}+K_{0}(I) u+\alpha_{0}(I) z\right], \\
C_{0}(I)= \begin{cases}C_{1}+C_{2}\left(1-e^{-C_{3}\left(I-I_{c}\right)}\right) & I>I_{c} \\
C_{4}+\frac{C_{4}-C_{1}}{I_{c}} I & I \leq I_{c},\end{cases} \\
\alpha_{0}(I)= \begin{cases}\alpha_{1}+\alpha_{2}\left(1-e^{-\alpha_{3}\left(I-I_{c}\right)}\right) & I>I_{c} \\
\alpha_{1}+\frac{\alpha_{4}-\alpha_{1}}{I_{c}} I & I \leq I_{c}, \\
\gamma_{0}(I)=-\gamma_{1}+\gamma_{2} I, & I>I_{c}\end{cases} \\
f_{Z 0}(I)=\left\{\begin{array}{cc}
f_{Z 1}+f_{Z 2}\left(1-e^{-f_{Z 3}\left(I-I_{c}\right)}\right) \\
f_{Z 4}+\frac{f_{Z 4}-f_{Z 1}}{I_{c}} I
\end{array}\right.
\end{gathered}
$$

where $\omega$ is the frequency of the excitation; $d_{1}, d_{2}, d_{3}$, and $d_{4}$ are constants; $C_{1}, C_{2}, C_{3}, C_{4}, K_{1}, K_{2}, \alpha_{1}, \alpha_{2}, \alpha_{3}, \alpha_{4}, f_{Z 1}$, $f_{Z 2}, f_{Z 3}$, and $f_{Z 4}$ are the constant parameters used to relate the characteristic shape parameters to current signal; $f_{Z 0}(I)$ is defined as the offset force of the MR damper; $I$ is the current signal; $I_{c}$ is the critical current in which the linear behavior changes into nonlinear one or vice versa. By using the above parameters the evolutionary variable $z$ can be modified as follows:

$$
\begin{aligned}
z(I)=\frac{1}{\sqrt{\gamma(I)}} \tanh \{\sqrt{\gamma(I)}[ & \dot{u}+\frac{1}{\sqrt{\gamma(I)}} \\
& \left.\left.\times a \tanh \left(\frac{f_{Z 0}(I) \sqrt{\gamma(I)}}{\alpha_{0}(I)}\right)\right]\right\}
\end{aligned}
$$

for $(z<0, x<0)$ or for $(z \geq 0, x<0)$,

$$
\begin{aligned}
z(I)=\frac{1}{\sqrt{\gamma(I)}} \tanh \{\sqrt{\gamma(I)}[ & \dot{u}+\frac{1}{\sqrt{\gamma(I)}} \\
& \left.\left.\times a \tanh \left(-\frac{f_{Z 0}(I) \sqrt{\gamma(I)}}{\alpha_{0}(I)}\right)\right]\right\}
\end{aligned}
$$

for $(z \geq 0, x \geq 0)$ or for $(z<0, x \geq 0)$.

It was demonstrated that the proposed model was very effective in predicting the behavior of MR dampers subjected to different harmonic excitations $(0.25,2.5,5.0,7.5$, and $10.0 \mathrm{~Hz})$ and various constant current signals $(0.00,0.25,0.50$, $0.75,1.00,1.25$, and $1.50 \mathrm{~A})$.

To apply the Bouc-Wen model by Dominguez et al. [64] to the high impact force estimation of the MR damper,
Xiang et al. [44] updated the equations of Dominguez et al. [64] to estimate the dynamic behaviors of MR dampers under high impact loads. Xiang et al. [44] modified the damping coefficient, the elastic coefficient, and the evolutionary variable as follows:

$$
\begin{gathered}
f_{\mathrm{MR}}=C_{0}(I) \dot{u}+K_{0}(I) u+\alpha_{0}(I) z+f_{s}, \\
C_{0}(I)=C_{R 1}+\left(C_{R 2} \times I\right), \\
K_{0}(I)=-K_{R 1}\left(e^{-I / K_{R 2}}\right)+K_{R 3}, \\
z(I)=\frac{1}{\sqrt{\gamma(I)}} \tanh \left\{\sqrt{\gamma(I)} \times\left[\dot{u}+\dot{u}_{h}(I)\right]\right\}, \\
\dot{u}_{h}=u_{h 1}-\left(u_{h 2} \times I\right),
\end{gathered}
$$

where $f_{s}$ is the offset force due to the accumulator; $C_{R 1}, C_{R 2}$, $K_{R 1}, K_{R 2}, u_{h 1}$, and $u_{h 2}$ are the characteristic shape parameters of the modified equations. It was demonstrated that the modified Bouc-Wen model is very effective in predicting the high impact forces of MR dampers under passive controlled case. However, it will be shown in this paper that the modified Bouc-Wen model is not effective in predicting various impact responses of MR dampers under random current signals. The simulation results are described in Section 4.2.1.

2.2. Bingham Model. A Bingham model is used to understand and predict the behavior of an MR damper by modeling the viscous magnetic liquid in it. It is an effective way to investigate the flow properties and yield stress of MR fluids in liquid, quasisolid, and solid phases. The equation of the Bingham model can be expressed as [65]

$$
f_{\mathrm{MR}}=c_{d} \dot{u}+\tau(\operatorname{sgn}(\dot{u}))
$$

where $c_{d}$ is the viscosity coefficient of MR fluids and $\tau$ represents the yield strength of the MR fluids. $\tau$ is formulated as follows:

$$
\tau=\left(\bar{a} \times I^{3}\right)+\left(\bar{b} \times I^{2}\right)+(\bar{c} \times I)+\bar{d},
$$

where $\bar{a}, \bar{b}, \bar{c}$, and $\bar{d}$ are the identification parameters for the current signal between $0 \mathrm{~A}$ and $2 \mathrm{~A}$. However, it is assumed that the Bingham model has a linear relationship between the stress and the rate of deflection when the yield stress exceeded. Due to the assumption on the linear postyield damping, the shear thinning observed in impact damper applications cannot be accounted for in the Bingham model. The results showed that the Bingham model would not be effective in reproducing the nonlinear impact behavior of $\mathrm{MR}$ dampers. In this context, different nonlinear SI frameworks, which are described below, are used to improve the performance on the MR damper impact response prediction under a variety of impact loads and current signals.

2.3. Neurofuzzy Model. A neurofuzzy model can be simply described as a system that integrates the neural network and fuzzy set theory [16]. Neural network is used to mimic the human brain to improve the pattern recognition and 


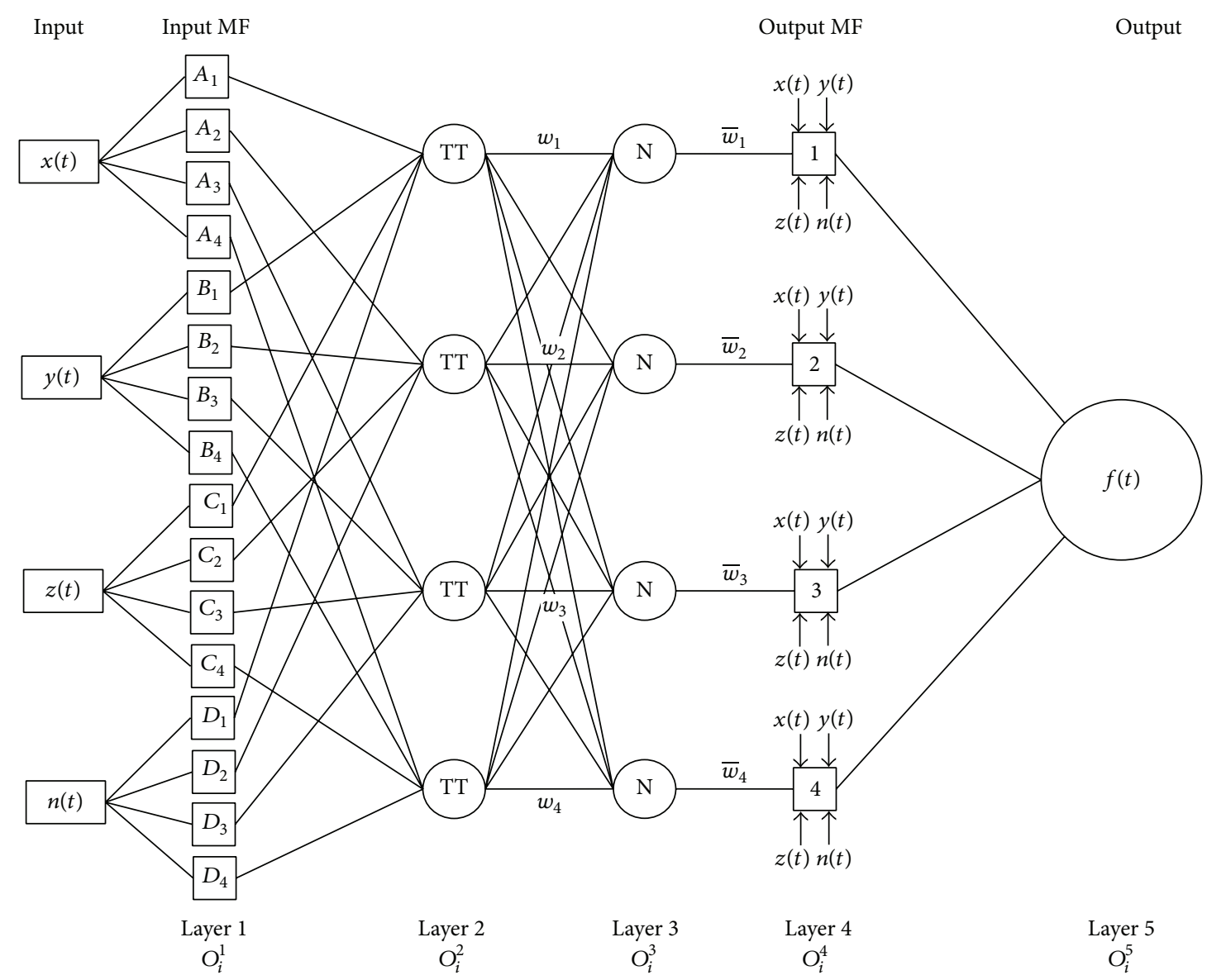

FIgURE 3: Typical neurofuzzy architecture.

the adaptability of the system, while fuzzy inference is used in the decision making. The premise parameters of the Takagi-Sugeno (TS) fuzzy model are determined using the grid partition approach. By using a backpropagation neural network learning algorithm, the consequent parameters of the model are updated until they reach the optimal solution [66]. A typical neurofuzzy system with four inputs and one output is presented in Figure 3.

After the data is processed in the current layer, it moves forward to the next layer. The process can be described as follows. (i) Layer 1 determines the fuzzy membership of inputs. (ii) The output of the Layer 2 is the product of all the incoming signals. (iii) In Layer 3, the data is normalized. (iv) Node functions are applied in Layer 4 to solve the output of each fuzzy rule. (v) Overall output of the fuzzy system is summated in Layer 5. A typical four-rule neurofuzzy model [67] is as follows:

Rule 1: If $x$ is $A_{1}, y$ is $B_{1}, z$ is $C_{1}, m$ is $D_{1}$,

$$
\text { then } f_{1}=p_{1} x+q_{1} y+k_{1} z+l_{1} n+r_{1}
$$

Rule 2: If $x$ is $A_{2}, y$ is $B_{2}, z$ is $C_{2}, m$ is $D_{2}$,

$$
\text { then } f_{2}=p_{2} x+q_{2} y+k_{2} z+l_{2} n+r_{2}
$$

Rule 3: If $x$ is $A_{3}, y$ is $B_{3}, z$ is $C_{3}, m$ is $D_{3}$, then $f_{3}=p_{3} x+q_{3} y+k_{3} z+l_{3} n+r_{3}$

Rule 4: If $x$ is $A_{4}, y$ is $B_{4}, z$ is $C_{4}, m$ is $D_{4}$,

then $f_{4}=p_{4} x+q_{4} y+k_{4} z+l_{4} n+r_{4}$,

where $x, y, z$, and $n$ are the inputs and $f$ is the output of the TS fuzzy system. The consequent parameters are defined as $p_{i}, q_{i}, k_{i}, l_{i}$, and $r_{i}$. The function of Layer 1 is presented as

$$
O_{i}^{1}=\mu\left[\begin{array}{c}
A_{i}(x) \\
B_{i}(y) \\
C_{i}(z) \\
D_{i}(n)
\end{array}\right],
$$

where $\mu$ is the appropriate parameterized membership function (MF). $O_{i}^{1}(i=1,2,3,4)$ is the output that specifies the degree to which the given input $x$ satisfies the quantifier $A$.

After the application of MFs to each input, the data moves to the second layer. The function of Layer 2 is presented as

$$
w_{i}=\mu A_{i}(x) \times \mu B_{i}(y) \times \mu C_{i}(z) \times \mu D_{i}(n), \quad i=1,2,3,4 .
$$




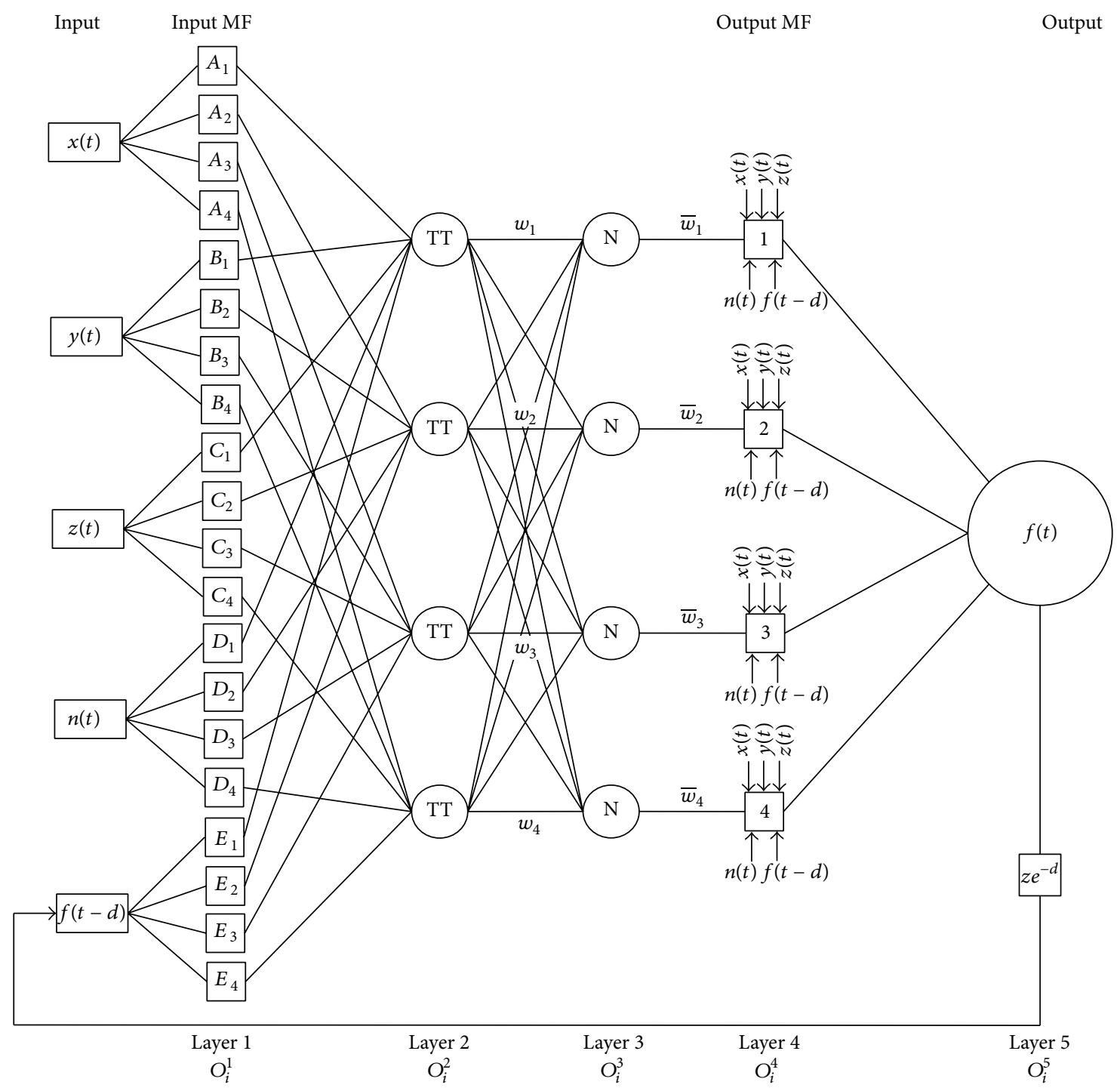

FigURE 4: OF neurofuzzy architecture showing four input and one output model.

The output of the Layer 2 is the product of all incoming inputs. In order to normalize the output of Layer 2, the ratio of the output is taken in Layer 3 as follows:

$$
\bar{w}_{i}=\frac{w_{i}}{w_{1}+w_{2}+w_{3}+w_{4}}, \quad i=1,2,3,4
$$

In Layer 4 , node functions $\left(f_{i}=p_{i} x+q_{i} y+k_{i} z+l_{i} n+r_{i}\right.$, $i=1,2,3,4)$ are applied to output of Layer 3 :

$$
\begin{array}{r}
O_{i}^{4}=\bar{w}_{i} \times f_{i}=\bar{w}_{i} \times\left(p_{i} x+q_{i} y+k_{i} z+l_{i} n+r_{i}\right), \\
i=1,2,3,4 .
\end{array}
$$

As a last step, Layer 5 summates the layer inputs as follows:

$$
\begin{array}{r}
O_{i}^{5}=\text { overall output }=\sum_{i} \bar{w}_{i} \times f_{i}=\frac{\sum_{i} w_{i} \times f_{i}}{\sum_{i} w_{i}} \\
i=1,2,3,4 .
\end{array}
$$

In the optimization of the results, the neurofuzzy system uses adjustable parameters such as the number of MFs, types of MFs, the iteration, and the step size. Various input-output data sets with different MF types are studied in this study in order to improve the effectiveness of the neurofuzzy model. In order to obtain input-output data for training and validating the neurofuzzy model, a number of experimental studies are performed. The responses such as acceleration and deflection are obtained under a variety of combinations of the impact loads and the current signals. In this study, the displacement, acceleration, velocity, and current signals are used to train the neurofuzzy model to model the impact force of the MR damper. At the end of the research, it is observed that about $75 \%$ of the actual impact force of the MR damper is correctly predicted by the neurofuzzy model. Howerer, only $44 \%$ of the peak values of impact forces are accurately predicted. It is also observed that the effectiveness of peak impact value predictions decreases as the level of the impact loads increases. In high impact scenarios, the MR damper 
model in the controlled structure may be effective due to the underestimated impact load when the neurofuzzy cannot predict the peak forces. In order to increase the accuracy between the trained and the actual high impact test data, a slightly modified fuzzy model can be used, which is defined below. It uses the outputs of the previous steps to predict the features of the following output.

\subsection{Output Feedback- (OF-) Based Neurofuzzy Model. The} OF neurofuzzy model with four inputs and one output is presented in Figure 4.

Although the architectures of both neurofuzzy and OF neurofuzzy models are similar, the OF neurofuzzy model uses the observations obtained from the previous steps to predict the features of the following output. The unit-time delay operator block, $z e^{-d}$, is used to implement the proposed OF neurofuzzy model [68]. The dynamic system is approximated as a functional representation of the time lagged inputs and outputs [69]. The model preserves the time sequence of the output vector and utilizes the past of the time series as an input. The input-output mapping can be expresed as follows:

$$
f_{j}(t)=f\left(\operatorname{in}_{j}^{t}, f^{t-d}, e^{t-d}\right)+e(t), \quad j=1,2,3,4,
$$

where in $_{j}^{t}$ represents the input, $f^{t}$ is the output, and $e^{t}$ is the error for time $t$. In this study, the time delay term $d$ is assigned as 1 , which means that the model uses the observations from the previous step $(t-1)$ to estimate the output at time $t$. The OF neurofuzzy model is as follows:

$$
O_{j}^{5}=\text { overall output }=\sum_{j} \bar{w}_{j} \times f_{j}=\frac{\sum_{j} w_{j} \times f_{j}}{\sum_{j} w_{j}} .
$$

It is observed that the OF neurofuzzy approach increases the accuracy of the trained model significantly. The accuracy of peak response value predictions is about over $97 \%$. The simulation results will be described in the following section.

\section{Experimental Setup}

A set of experimental tests are conducted to study the effectiveness of the proposed models on anticipating the nonlinear behavior of MR dampers under a variety of high impact loads. The proposed test framework includes drop tower tests, MR dampers, a data acquisition system, and sensors.

3.1. Drop Tower Test Facility. The high impact load test facility in Smart Impact Mitigation and Mechanics (SIMM) Laboratory in the Civil and Environmental Engineering Department at Worcester Polytechnic Institute (WPI) has been used to apply the controlled impact loads to the MR damper. The maximum capacity to apply the impact load of the testing facility is $22,500 \mathrm{~kg}$. In this study, the impact loads are applied by releasing a falling drop-mass from different combinations of the drop release heights.

3.2. Magnetorheological (MR) Dampers. In general, an MR damper consists of a hydraulic cylinder, the magnetic coils,

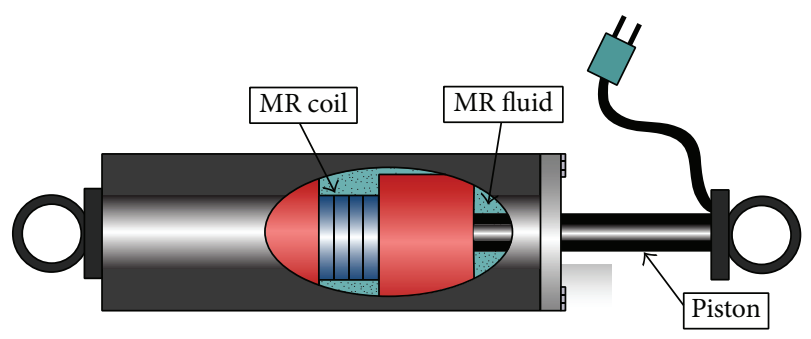

FIGURE 5: Schematic of RD-8040-1 MR damper.

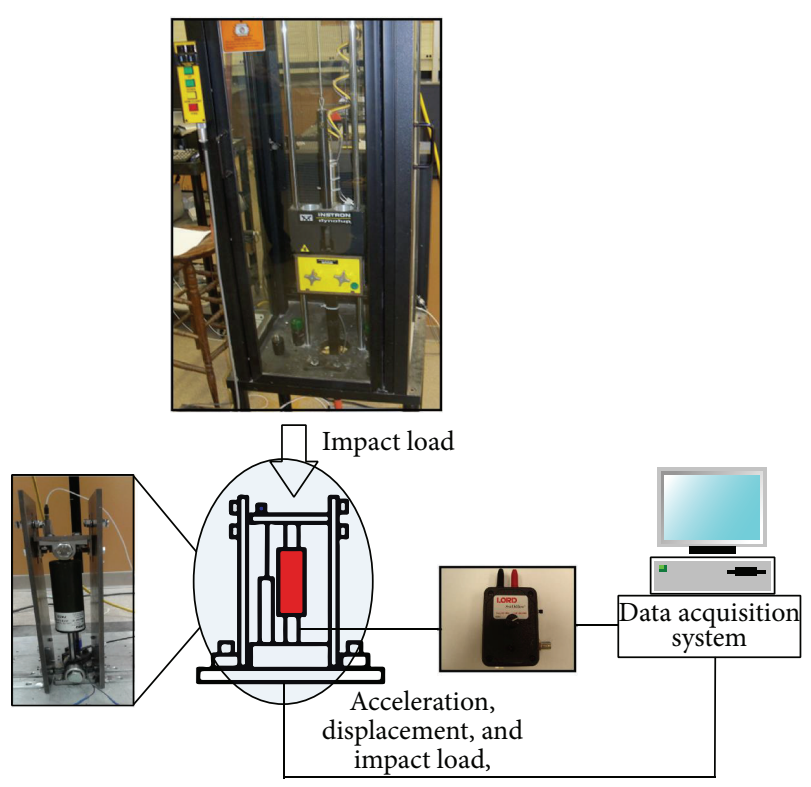

FIgURE 6: Details of the test framework.

and MR fluids. The MR fluid consists of micron-sized magnetically polarized particles within an oil-type fluid [13]. Some of the distinguishing characteristics of MR dampers are can be listed as follows. (i) MR dampers require low power sources when they are operated as active controllers. (ii) The performance is stable in a broad range of temperatures. (iii) They have a very fast response time. (iv) They have a high yield stress level $[15,23]$. The RD-8040-1-type MR damper developed by Lord Corporation is used in the experimental study (Figure 5).

A test framework as depicted in Figure 6 is prepared. An MR damper is fixed to the ground and the lateral plates to prevent it from shifting during the application of the high impact loading. To apply the impact loads and connect the sensors, a special housing system is manufactured. The lateral plates and the impact plate are assembled with a special rail system and oiled before each test in order to minimize the friction. For the consistency, the load is applied to the center of the impact plate.

3.3. Data Acquisition. During the impact tests, a National Instruments (NI) LabView data acquisition is used to obtain the acceleration, deflection, impact force, and current signal data. The displacement data is measured by R.D.P. product 


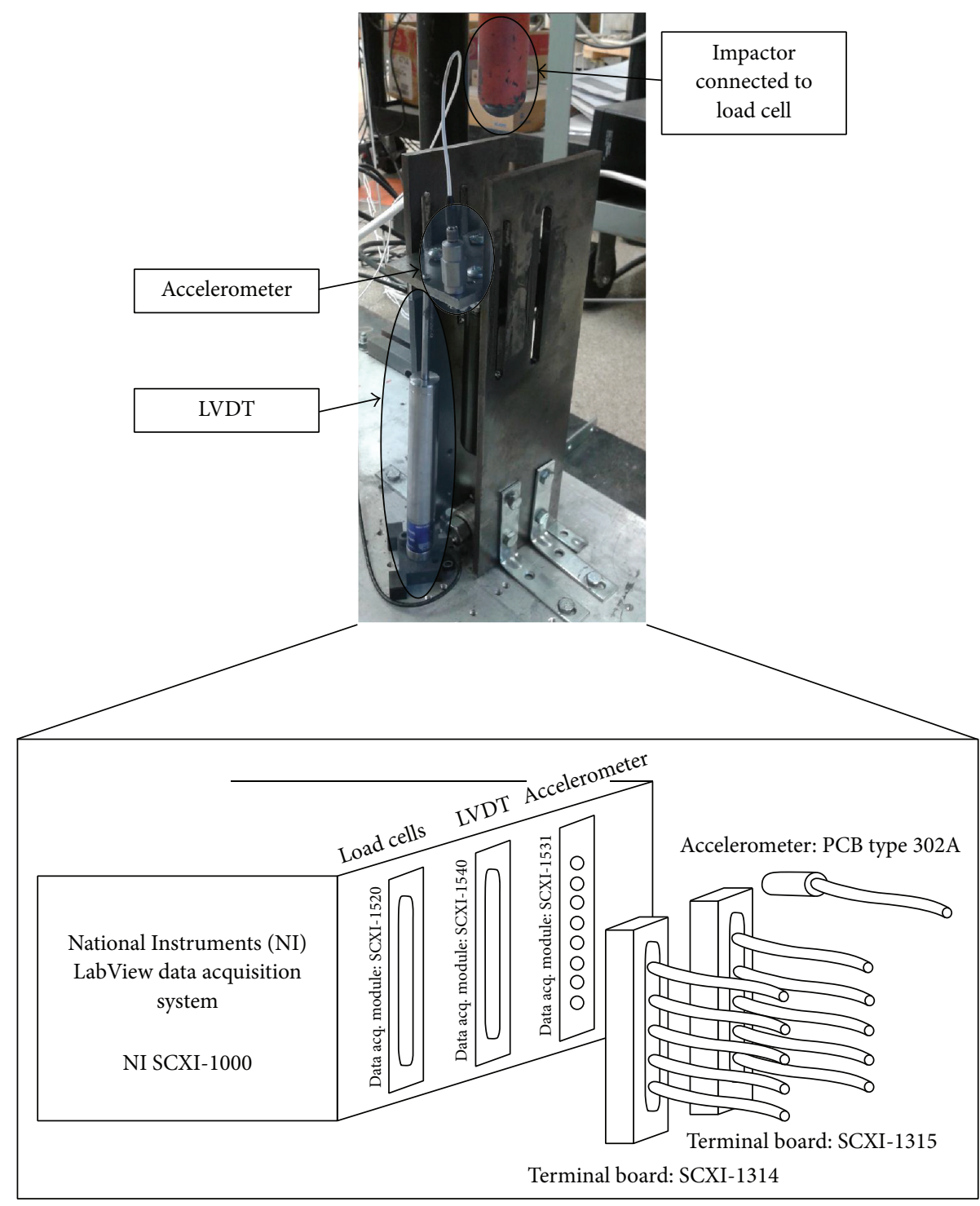

FIGURE 7: Configuration of the data acquisition system.

ACT1000A-type LVDT, while a PCB-type 302A accelerometer and a 4,500 kg capacity Central HTC-10K type load cells are used in the acceleration and impact force measurements, respectively. As a sampling rate of the data acquisition system, 10,000 data points per second are selected. The locations of the sensors are depicted in Figure 7.

3.4. Test Details. In this paper, all the data is partitioned into three sets: training, validation, and testing. First, the proposed models are trained by pairing the input signals with the expected output signals. Then the trained models are evaluated using different data sets that are not used for the training process: various design parameters such as membership functions and the model architecture such as the number of input signals are evaluated through the validation. The determination of the best model is achieved through an iterative process. The final model is further tested using different data sets that are not used for both the training and validation processes. Details of the performed tests can be found in Table 1.

Experimental study contains a total of 225 impact tests that investigate the dynamic responses of the MR damper under five different drop release heights $(65,130,254,380$, and $500 \mathrm{~mm}$ ) by various current signals. Three types of current signals are used in the tests such as several constants $(0,0.2$, $0.6,1,1.5$, and $1.9 \mathrm{~A})$, the sinusoidal signals with different frequencies $(0.75,1,1.5,2,3,5,7$, and $10 \mathrm{~Hz})$, and random signals ( $0 \mathrm{~A}-1.9 \mathrm{~A})$. The high impact test is repeated for each current level.

\section{System Identification Results}

\subsection{Parameter Setting}

4.1.1. Bouc-Wen Model. The parameters of the impact BoucWen model are adopted from Xiang et al. [44] as shown in Table 2. 
TABLE 1: Experimental test details.

\begin{tabular}{|c|c|c|c|c|c|}
\hline Trained data & $\begin{array}{l}\text { Case studies } \\
\text { Validation data }\end{array}$ & Test data & Drop release height (mm) & Type of output signal & Impact velocity $(\mathrm{mm} / \mathrm{s})$ \\
\hline 6 cases & 6 cases & 6 cases & \multirow{3}{*}{65} & Constant & \\
\hline 8 cases & 8 cases & 8 cases & & Sinusoidal & 1129 \\
\hline 1 case & 1 case & 1 case & & Random & \\
\hline 6 cases & 6 cases & 6 cases & \multirow{3}{*}{130} & Constant & \\
\hline 8 cases & 8 cases & 8 cases & & Sinusoidal & 2258 \\
\hline 1 case & 1 case & 1 case & & Random & \\
\hline 6 cases & 6 cases & 6 cases & \multirow{3}{*}{254} & Constant & \\
\hline 8 cases & 8 cases & 8 cases & & Sinusoidal & 4412 \\
\hline 1 case & 1 case & 1 case & & Random & \\
\hline 6 cases & 6 cases & 6 cases & \multirow{3}{*}{380} & Constant & \\
\hline 8 cases & 8 cases & 8 cases & & Sinusoidal & 6600 \\
\hline 1 case & 1 case & 1 case & & Random & \\
\hline 6 cases & 6 cases & 6 cases & \multirow{3}{*}{500} & Constant & \\
\hline 8 cases & 8 cases & 8 cases & & Sinusoidal & 8685 \\
\hline 1 case & 1 case & 1 case & & Random & \\
\hline
\end{tabular}

TABle 2: Parameters of Bouc-Wen model.

\begin{tabular}{lc}
\hline Parameter & Value \\
\hline$C_{R 1}$ & $1528 \mathrm{~N} \cdot \mathrm{s} \cdot \mathrm{m}^{-1}$ \\
$C_{R 2}$ & $1994 \mathrm{~N} \cdot \mathrm{s} \cdot \mathrm{m}^{-1}$ \\
$K_{R 1}$ & $53346 \mathrm{~N} \cdot \mathrm{m}^{-1}$ \\
$K_{R 2}$ & $69003 \mathrm{~N} \cdot \mathrm{A}^{-1}$ \\
$K_{R 3}$ & 0.3584 \\
$\gamma_{1}$ & $280 \mathrm{~m}^{-2}$ \\
$\gamma_{2}$ & $8.66 \mathrm{~m}^{-2}$ \\
$u_{h 1}$ & 0.0345 \\
$u_{h 2}$ & 0.0138 \\
$\alpha_{1}$ & $1514 \mathrm{~N} \cdot \mathrm{m}^{-1}$ \\
$\alpha_{2}$ & $4200 \mathrm{~N} \cdot \mathrm{m}^{-1}$ \\
$\alpha_{3}$ & $2.2 \mathrm{~A}^{-1}$ \\
$\alpha_{4}$ & $5728 \mathrm{~N} \cdot \mathrm{m}^{-1}$ \\
$I_{c}$ & $0.25 \mathrm{~A}$ \\
\hline
\end{tabular}

The result of the Bouc-Wen model is discussed in the following section.

4.1.2. Bingham Model. Table 3 shows the parameters used in the development of the impact Bingham model. The parameters come from the results of Fu et al. [65].

4.1.3. Neurofuzzy Model. To develop the neurofuzzy model, many sets of input and output data are collected and prepared for training, validation, and testing. In the simulation process, to get the best match, an iterative method is used by changing the training iteration, step size, and type and quantity of MFs. Figure 8 shows the type of MFs used. Table 4 depicts the effect of MFs on the accuracy of the developed neurofuzzy models.

After performing the extensive simulations, it was observed that the best match was obtained from the Gaussian
TABle 3: Parameters of Bingham model.

\begin{tabular}{lc}
\hline Parameter & Value \\
\hline$c_{d}$ & 252.0898 \\
$\bar{a}$ & -15.821146 \\
$\bar{b}$ & 27.469656 \\
$\bar{c}$ & 14.631534 \\
$\bar{d}$ & 2.229533 \\
\hline
\end{tabular}

MF. Hence, using the Gaussian MFs, the parametric studies on the combination of input-output data sets are conducted in this study. A total of 15 combinations are evaluated. Table 5 compares the performance of fuzzy models for different input data sets.

It is demonstrated that the choice of input-output data set has a significant effect on the accuracy of the neurofuzzy model. When the MR damper is modelled using a single input and single output data set, the accuracy of the model does not reach up to $50 \%$. To obtain a better performance, the number of inputs is increased step by step. The fitting rates of the fuzzy model are about over $50 \%$ for the three inputsone output data set. As seen from Table 5, the fuzzy model trained using the input-output data set that was used in Wang and $\mathrm{Hu}$ [56] produced around the fitting rate of $47 \%$, which is the case of 14 . The best model for identifying the nonlinear behavior of MR dampers is obtained by using four inputs-one output data set. It is found that all the defection, acceleration, and velocity data significantly contribute to the performance of the neurofuzzy model. Figure 9 shows a selected set of the input-output signals for training the neurofuzzy model, while Figures 10 and 11 depict the input-output data sets used in validation and testing. The deflection, acceleration, velocity, and current signals are used as the inputs while the high impact load applied on the MR damper is used as an output signal. 
TABLE 4: Simulation parameter studies.

\begin{tabular}{|c|c|c|c|c|c|c|}
\hline \multicolumn{4}{|c|}{ Inputs } & \multicolumn{2}{|l|}{ Output } & \multirow{2}{*}{ Accuracy (\%) } \\
\hline Deflection & Acceleration & Velocity & Current & Impact load & Niг type & \\
\hline & \multirow{5}{*}{\multicolumn{3}{|c|}{ Neurofuzzytraining (4 inputs-1 output) }} & & Gaussian & 74.68 \\
\hline & & & & & Bell & 68.57 \\
\hline & & & & & Triangular & 71.37 \\
\hline & & & & & Sigmoidal & 73.75 \\
\hline & & & & & Trapezoidal & 65.10 \\
\hline
\end{tabular}

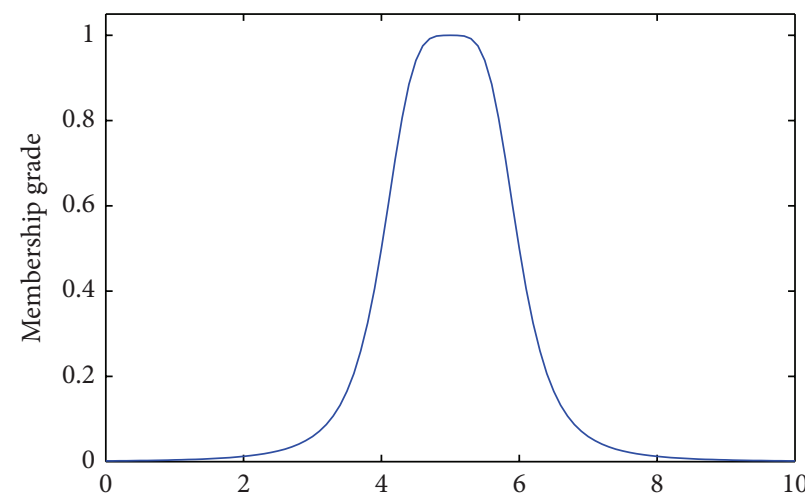

(a)

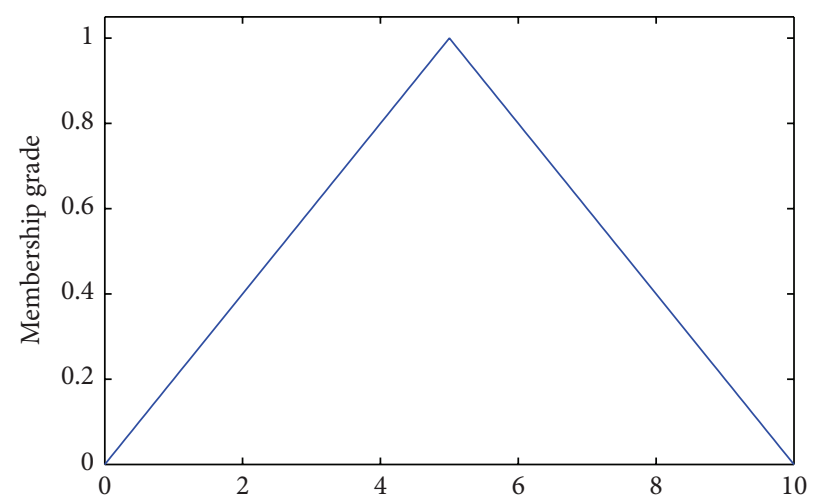

(c)

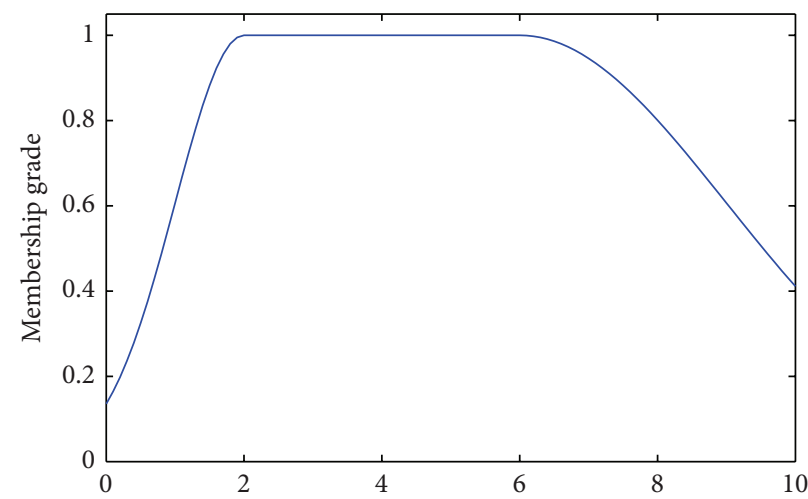

(b)

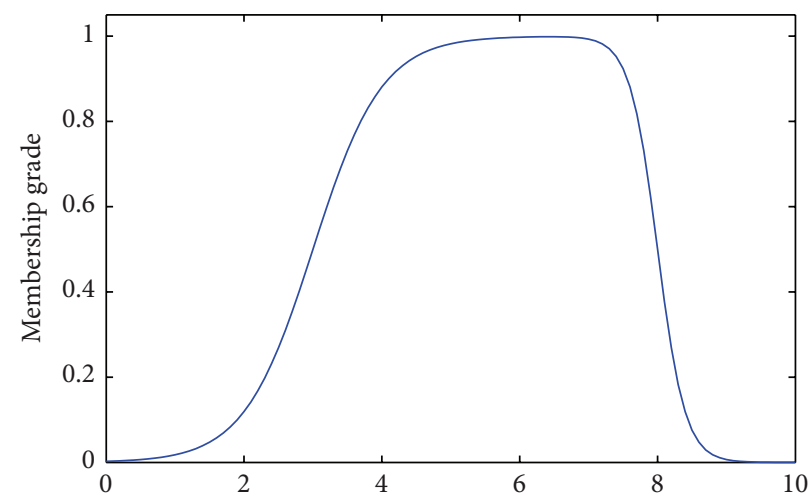

(d)

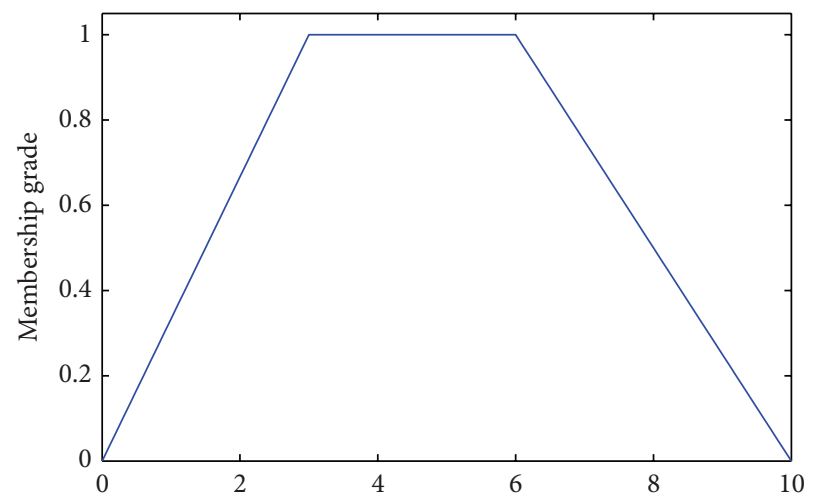

(e)

Figure 8: The type of MF: (a) Gaussian MF, (b) bell MF, (c) triangular MF, (d) sigmoidal MF, and (e) trapezoidal MF. 
TABLE 5: Simulation parameter studies for neurofuzzy models.

\begin{tabular}{|c|c|c|c|c|c|c|}
\hline \multirow{2}{*}{ Model number } & \multicolumn{6}{|c|}{ Input } \\
\hline & & Deflection & Acceleration & Velocity & Current & Accuracy (\%) \\
\hline 1 & \multirow{4}{*}{1 input-1 output } & + & & \multirow{4}{*}{+} & & 32.52 \\
\hline 2 & & & + & & & 40.34 \\
\hline 3 & & & & & & 39.72 \\
\hline 4 & & & & & + & 2.09 \\
\hline 5 & \multirow{6}{*}{2 inputs-1 output } & + & + & & & 60.65 \\
\hline 6 & & + & & + & & 63.4 \\
\hline 7 & & + & & & + & 37.32 \\
\hline 8 & & & + & + & & 61.74 \\
\hline 9 & & & + & & + & 41 \\
\hline 10 & & & & + & + & 41.58 \\
\hline 11 & \multirow{4}{*}{3 inputs- 1 output } & + & + & + & & 68.23 \\
\hline 12 & & + & + & & + & 58.34 \\
\hline 13 & & + & & + & + & 56.55 \\
\hline 14 & & & + & + & + & 47.45 \\
\hline 15 & 4 inputs-1 output & + & + & + & + & 74.68 \\
\hline
\end{tabular}

TABLE 6: Simulation parameter studies for the OF neurofuzzy models.

\begin{tabular}{|c|c|c|c|c|c|c|}
\hline \multirow{2}{*}{ Model number } & \multicolumn{6}{|c|}{ Input } \\
\hline & & Deflection & Acceleration & Velocity & Current & Accuracy (\%) \\
\hline 1 & \multirow{4}{*}{1 input-1 output } & + & & \multirow{4}{*}{+} & & 85.66 \\
\hline 2 & & & + & & & 86.16 \\
\hline 3 & & & & & & 85.68 \\
\hline 4 & & & & & + & 85.67 \\
\hline 5 & \multirow{6}{*}{2 inputs-1 output } & + & + & & & 91.05 \\
\hline 6 & & + & & + & & 91.05 \\
\hline 7 & & + & & & + & 92.02 \\
\hline 8 & & & + & + & & 91.13 \\
\hline 9 & & & + & & + & 91.35 \\
\hline 10 & & & & + & + & 91.08 \\
\hline 11 & \multirow{4}{*}{3 inputs- 1 output } & + & + & + & & 99.81 \\
\hline 12 & & + & + & & + & 99.78 \\
\hline 13 & & + & & + & + & 99.79 \\
\hline 14 & & & + & + & + & 99.81 \\
\hline 15 & 4 inputs-1 output & + & + & + & + & 99.84 \\
\hline
\end{tabular}

4.1.4. The OF Neurofuzzy Model. The same parametric studies are performed to investigate the effect of the input-output data set on the performance of the OF neurofuzzy model. The performance of the models for different input data sets are evaluated in Table 6.

In general, the behavior of the MR damper is a function of the system responses, for example, velocity, displacement, and acceleration, among others as well as current signals. To find the best model, both the model architecture such as the number and type of input variables and the fuzzy model parameters (i.e., number and type of membership functions) are investigated. Among them, the model without current signals can be considered as a passive shock absorber. It is observed that using current signals, as an input, enhances the accuracy of the prediction model.
Tables 5 and 6 showed that the accuracy of the neurofuzzy models can be enhanced by increasing the number of inputs. Note that Table 5 shows the results of the neurofuzzy model while Table 6 represents the performance of the output-feedback neurofuzzy model. However, the results demonstrated that the OF neurofuzzy model outperforms the neurofuzzy model. For example, the 4 inputs- 1 output OF neurofuzzy model has predicted $99 \%$ of the impact data correctly, while the accuracy of the neurofuzzy model with the same input-output data is about $75 \%$. It is seen that the accuracy of the OF neurofuzzy model is over $85 \%$ for all input-output data sets.

In order to be persistent in the evaluation of the results, the same input-output data set was used to train the OF neurofuzzy model with the bare neurofuzzy model. 

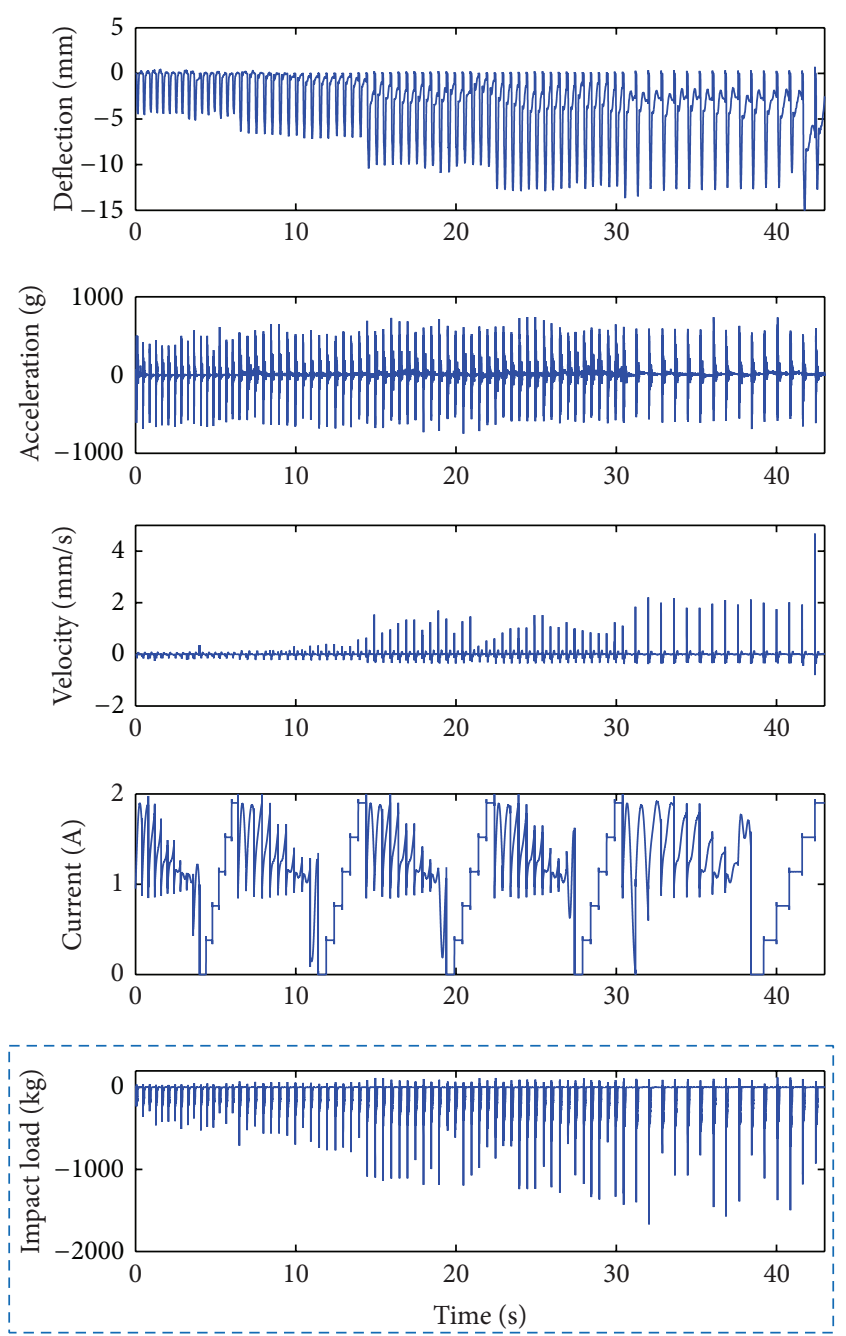

FIGURE 9: Input-output data sets to train the neurofuzzy models.

\subsection{System Identification Results}

4.2.1. Bouc-Wen Model. The time history responses of the Bouc-Wen model employing various currents and different drop release heights are depicted in Figure 12.

It is shown from Figure 12 that the Bouc-Wen model does not capture the nonlinear behavior of the MR damper system under a variety of impact loads and current signals. The fitting rates of models are about $3 \%$. This could be inferred from two facts. (1) The parameters of the Bouc-Wen model [44] are determined using a single current level. Thus, the model may not accurately predict the experimental data for other currents levels. (2) The model only uses one auxiliary nonlinear differential equation to describe the hysteretic behavior of the MR damper, which makes it very challenging to incorporate different impact load cases with a variety of current signals.

4.2.2. Bingham Model. Figure 13 compares the real measured impact load with the estimates from the Bingham models.
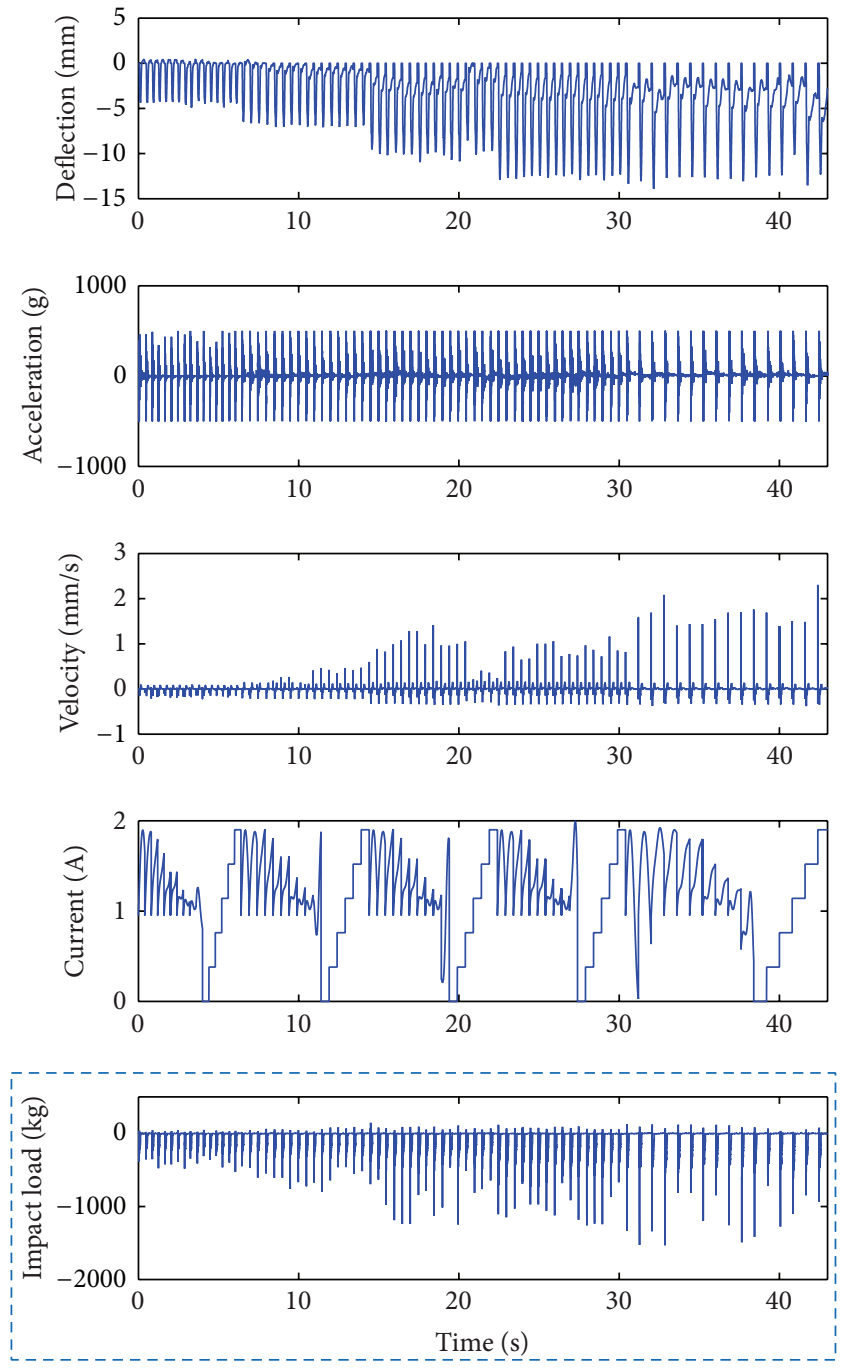

FIGURE 10: Input-output data sets to validate the neurofuzzy models.

As seen in Figure 13, the predicted results of the Bingham model are not in an agreement with the measurements of the actual impact loads. Only 5\% of the MR damper behavior under a variety of impact loadings and control inputs is accurately predicted. As previously discussed, it is difficult to predict the complicated behavior of the MR dampers under a variety of impact forces and current signals. The reason is that the Bingham model is implemented with constant parameters.

4.2.3. Neurofuzzy Modeling. A variety of the neurofuzzy model architectures have been considered, including various combinations of input and output data sets. Figure 14 represents a selected architecture of the neurofuzzy model.

Figure 15 compares the real measured impact load data with the estimations of the neurofuzzy model for five different force levels under various current levels.

The results show that the neurofuzzy predictions give reasonable match between the trained and actual test data. The fitting rate of the model for the four inputs-one output 

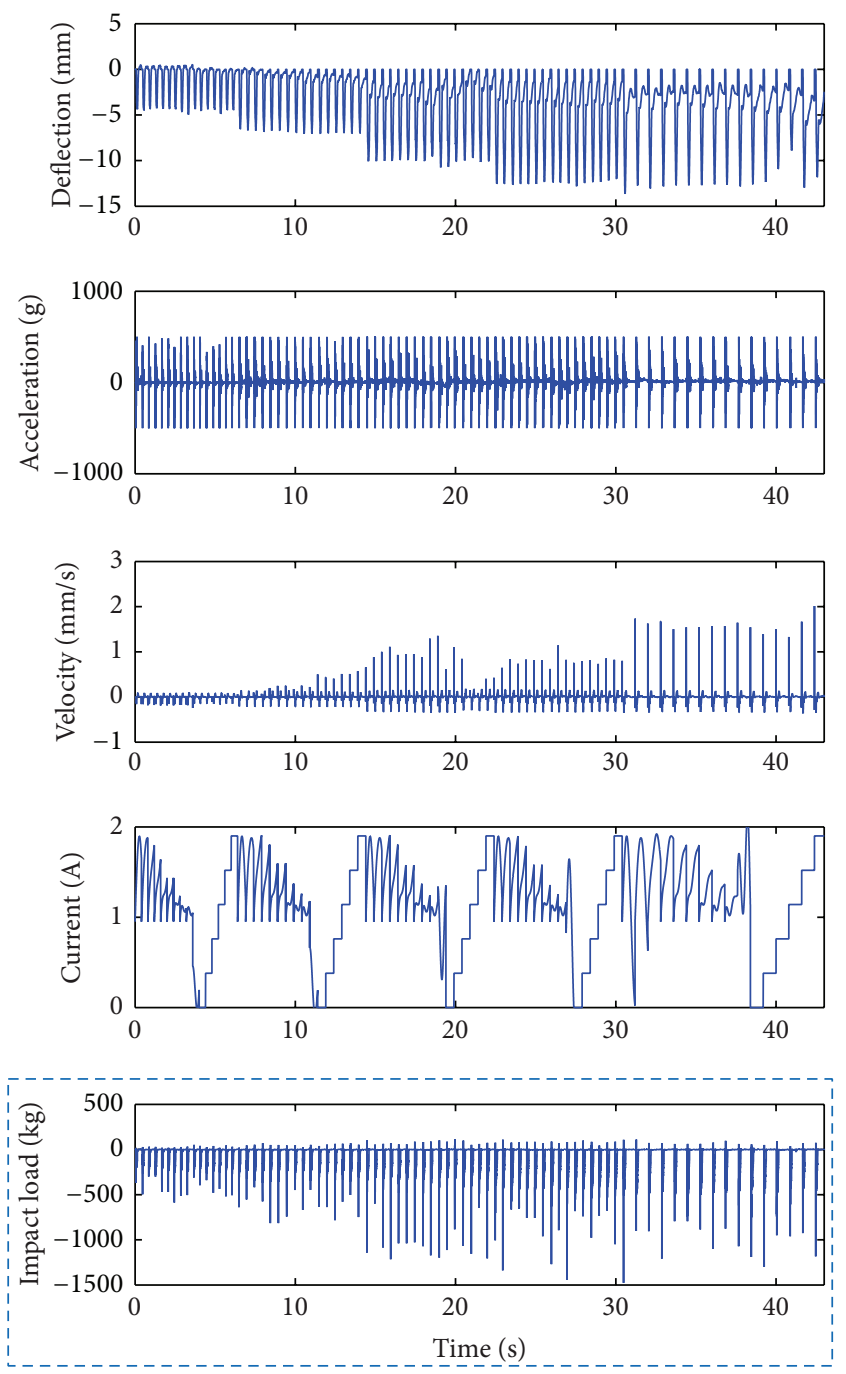

FIGURE 11: Input-output data sets to test the neurofuzzy models.

data sets is about $75 \%$. However, as mentioned in the previous sections, the performance of the neurofuzzy model to capture the peak impact values decreases as the impact loads increase. The underestimation of the impact load in the control system design can reduce the effectiveness of the MR damper to dissipate the impact energy. For this reason, the OF neurofuzzy model is used to increase the accuracy of the predictions.

4.2.4. The OF Neurofuzzy Modeling. Figure 16 represents the conceptual configuration of the proposed OF neurofuzzy models.

The selected MFs of the OF neurofuzzy model are presented in Figure 17. Left column shows the initial MFs values, while the right column represents the optimally tuned MFs.

Figure 18 depicts the time steps and the iteration of the OF neurofuzzy model. For the model, a total of iterations of

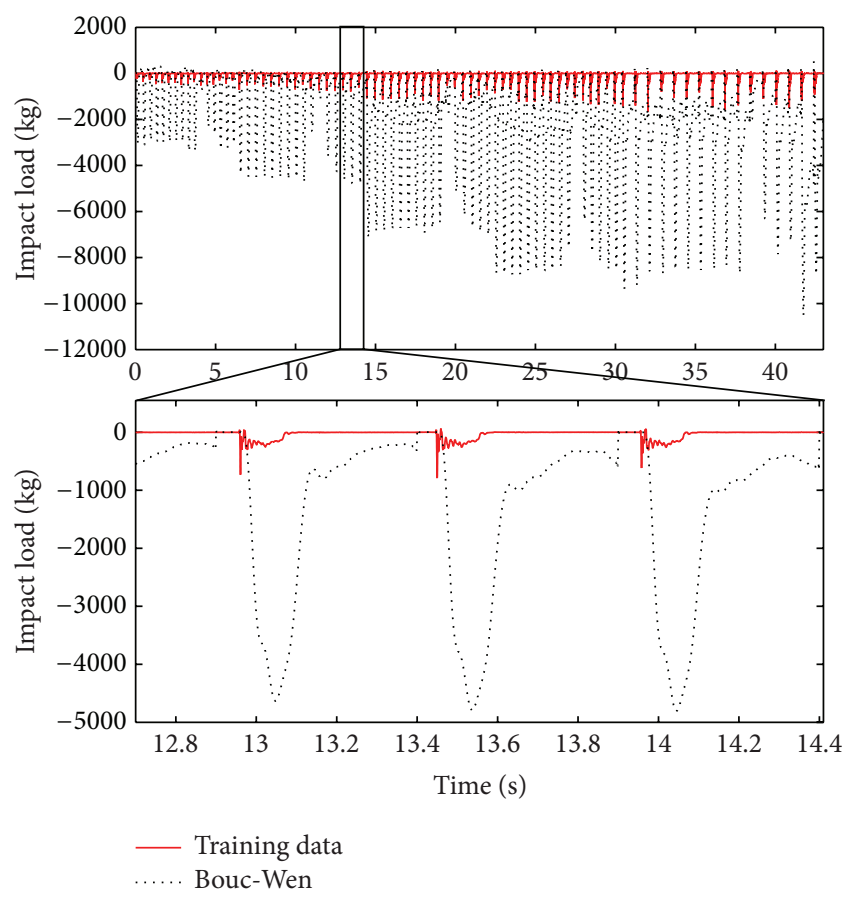

FIGURE 12: Comparison of the impact load measurements with the Bouc-Wen model for various currents and drop release heights.

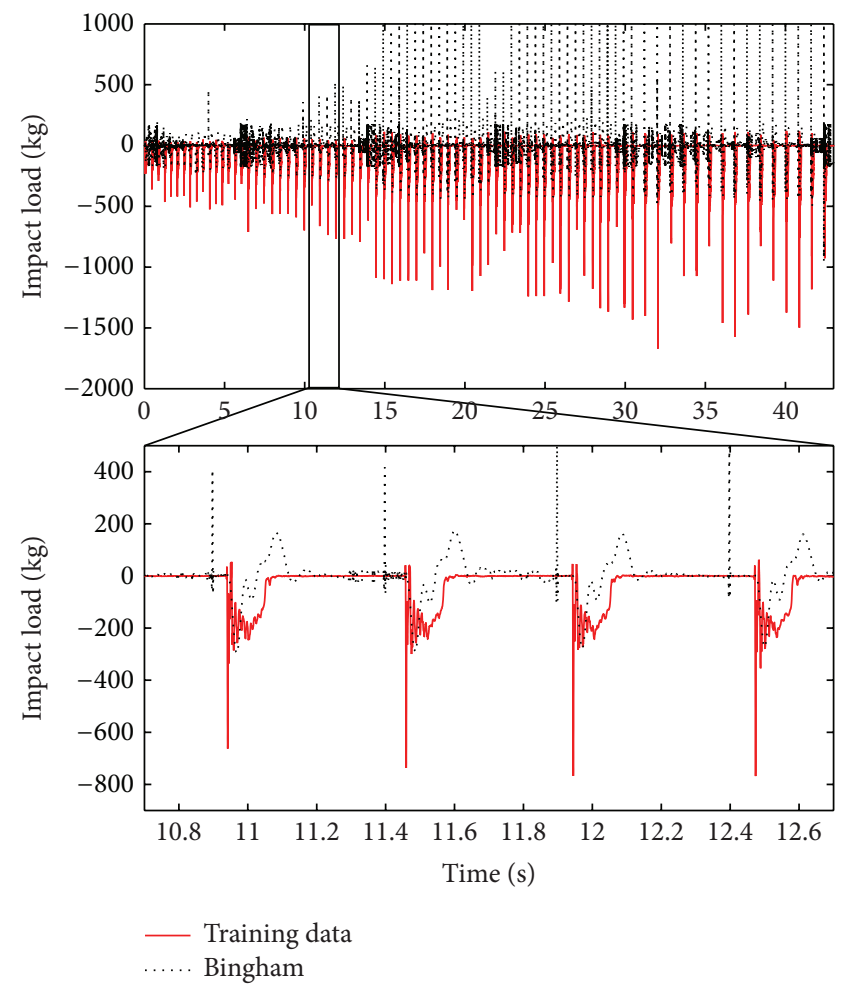

FIGURE 13: Comparison of the impact load measurements with Bingham plastic model for various currents and drop release heights.

10 are assumed adequate since the modeling performance is satisfied with the 10 iterations. 
TABLE 7: Error quantities of the SI models.

\begin{tabular}{|c|c|c|c|c|c|}
\hline & & $J_{1}$ (unit) & $J_{2}$ (unit) & $J_{4}$ (unit) & $J_{4} \%$ \\
\hline \multirow{4}{*}{ Training } & Bouc-Wen & $1.532 e+4$ & $1.996 e+3$ & $1.083 e-5$ & 2.27 \\
\hline & Bingham & $1.663 e+3$ & 55.138 & $1.836 e-5$ & 5.70 \\
\hline & Neurofuzzy & $1.1193 e+3$ & 26.216 & $1.957 e-5$ & 74.67 \\
\hline & OF neurofuzzy & 131.55 & 1.028 & $1.605 e-7$ & 99.84 \\
\hline \multirow{8}{*}{ Test } & Bouc-Wen-1 & $1.032 e+4$ & $2.125 e+3$ & $1.083 e-5$ & 2.09 \\
\hline & Bouc-Wen-2 & $1.032 e+4$ & $2.120 e+3$ & $1.083 e-5$ & 2.10 \\
\hline & Bingham-1 & $1.668 e+3$ & 55.715 & $7.594 e-5$ & 5.42 \\
\hline & Bingham-2 & $1.668 e+3$ & 55.722 & $4.556 e-5$ & 5.43 \\
\hline & Neurofuzzy-1 & $1.054 e+3$ & 26.241 & $8.089 e-6$ & 74.28 \\
\hline & Neurofuzzy-2 & $1.008 e+3$ & 26.111 & $7.594 e-5$ & 73.59 \\
\hline & OF neurofuzzy-1 & 184.59 & 1.027 & $2.966 e-8$ & 99.76 \\
\hline & OF neurofuzzy-2 & 240.38 & 1.045 & $4.093 e-7$ & 99.72 \\
\hline
\end{tabular}

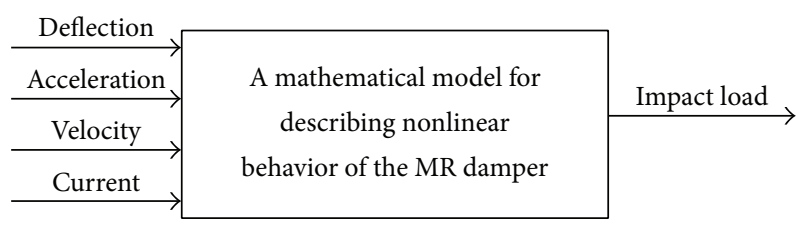

FIGURE 14: Configuration of the neurofuzzy model: impact load prediction.

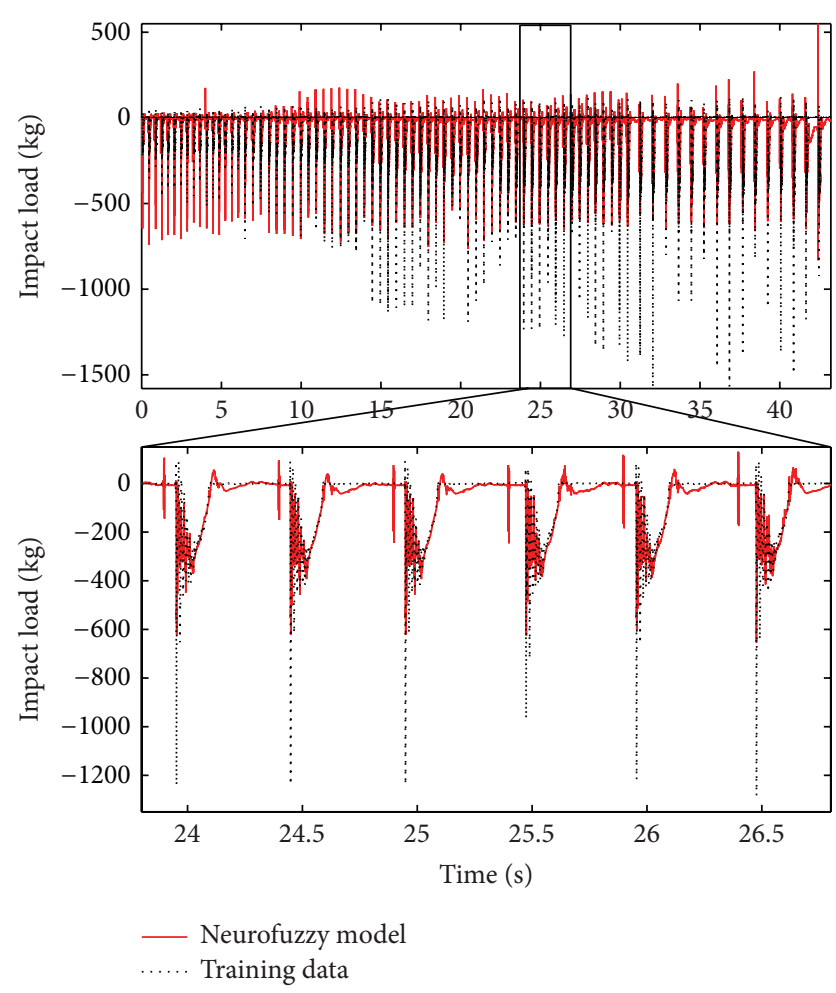

FIGURE 15: Neurofuzzy training results: constant, sinusoidal, and random currents for different drop release heights.

With these parameter settings, Figure 19 compares the measured force of the MR damper with the predicted force of the OF neuro-fuzzy model. The MR damper forces were

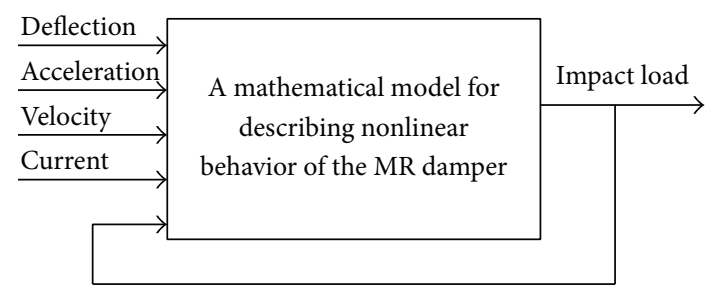

FIGURE 16: Configuration of the OF neurofuzzy model: impact load prediction.

measured under various control signals (constant, sinusoidal, and random) and a variety of impact loads.

As can be seen from the Figure 19 there is a great agreement between the fuzzy estimates and the original measurements. It is expected that the identified model that incorporates a variety of control signals such as the constant, sinusoidal, and random current signals will be useful to smart control system design to effectively dissipate the high impact energy [70].

To generalize the trained model, different data sets that are not used for the training process are used for testing the trained fuzzy model. Figures 20 and 21 exhibit the graphs of validated and test data sets.

As shown in figures, the proposed OF neurofuzzy models precisely predict the impact force of the MR damper. To investigate the constitutive relationship of the proposed model, hysteric response behaviors such as impact forcedisplacement and impact force-velocity curves are also modeled. Figures 22, 23, and 24 depict the comparison of the measured impact force-displacement and impact forcevelocity curves with the predictions of the OF neurofuzzy models. Figure 22 shows the impact force-displacement and impact force-velocity curves for the MR damper subjected to different impact loads and sinusoidal current signal, while Figures 23 and 24 show the same curves for random and constant current signals, respectively. The simulation results demonstrate that the OF neurofuzzy model is very effective in predicting the hysteric response behaviors of MR dampers under high impact loads. 

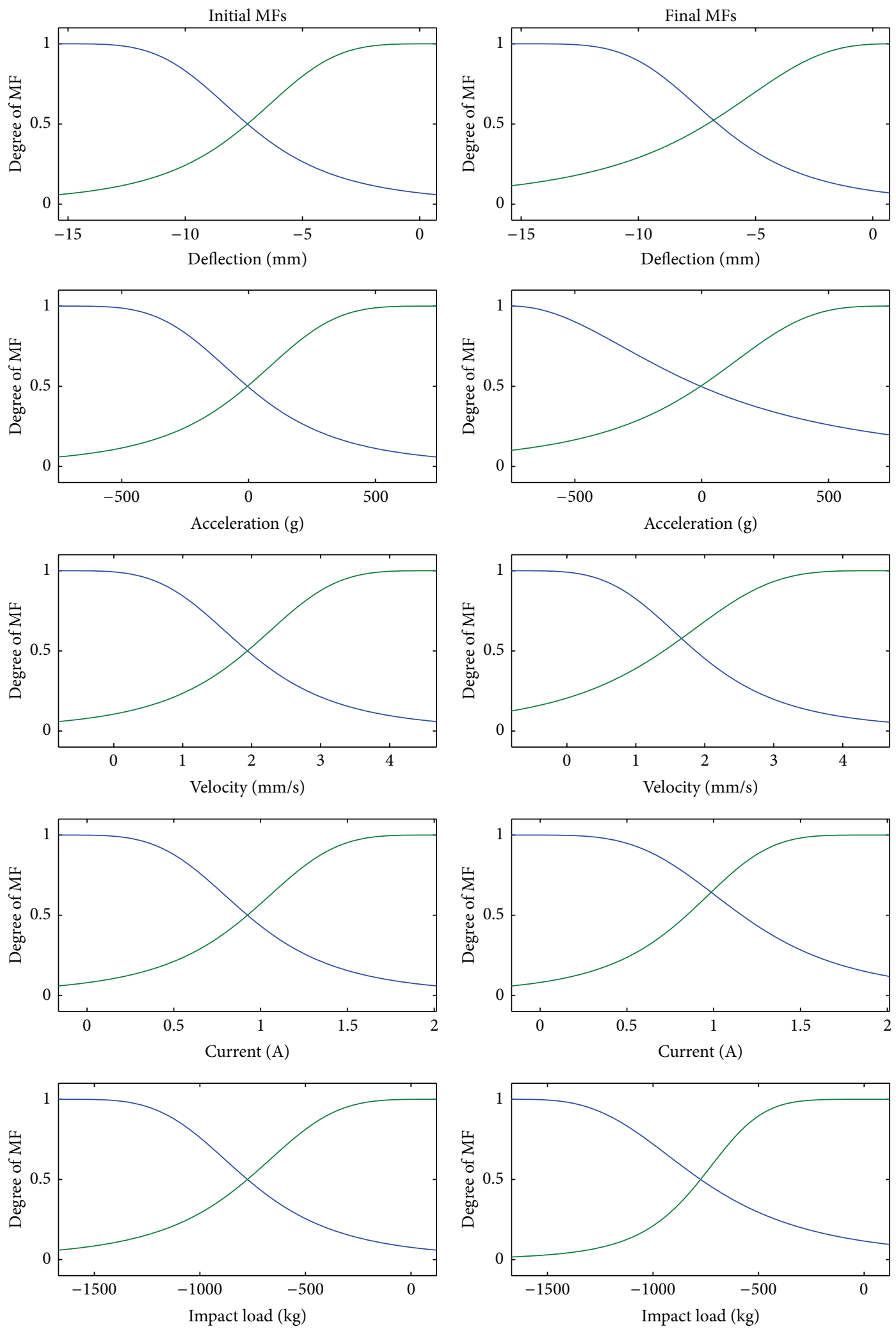

FIGURE 17: Initial and final membership functions. 


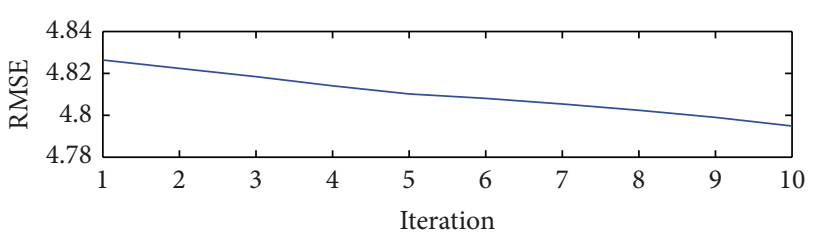

FIGURE 18: Iteration.
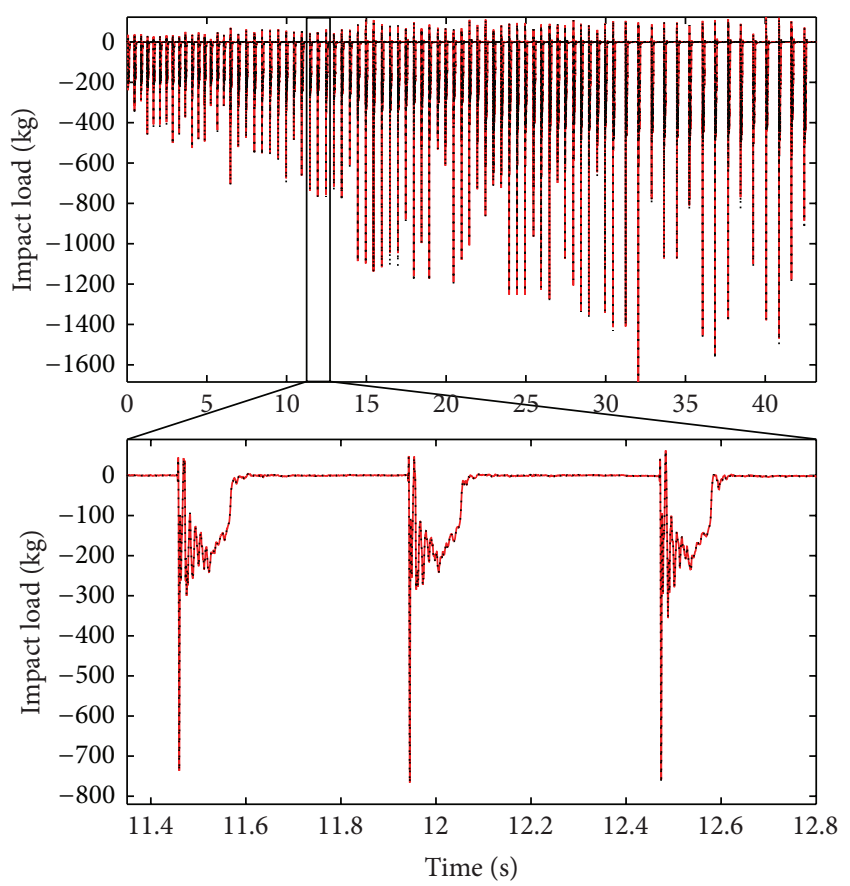

— OF neurofuzzy model

..... Training data

FIGURE 19: OF neurofuzzy training results: constant, sinusoidal, and random currents for different drop release heights.

4.3. Evaluation of Results. Several evaluation indices are also used to quantify the performance of the proposed neurofuzzy models. As a first evaluation index, the maximum absolute error is calculated as

$$
J_{1}=\max |\widehat{y}-\tilde{y}|,
$$

where $\hat{y}$ is the trained data and $\tilde{y}$ is the actual measurements. Second evaluation criterion is defined as the mean of absolute error

$$
J_{2}=\operatorname{mean}|\widehat{y}-\tilde{y}| .
$$

Third criterion index is minimum absolute error

$$
J_{3}=\min |\widehat{y}-\tilde{y}| \text {. }
$$

The fourth evaluation index is formulated as follows:

$$
J_{4}=\left[1-\frac{\operatorname{var}(\hat{y}-\tilde{y})}{\operatorname{var}(\hat{y})}\right] \times 100,
$$

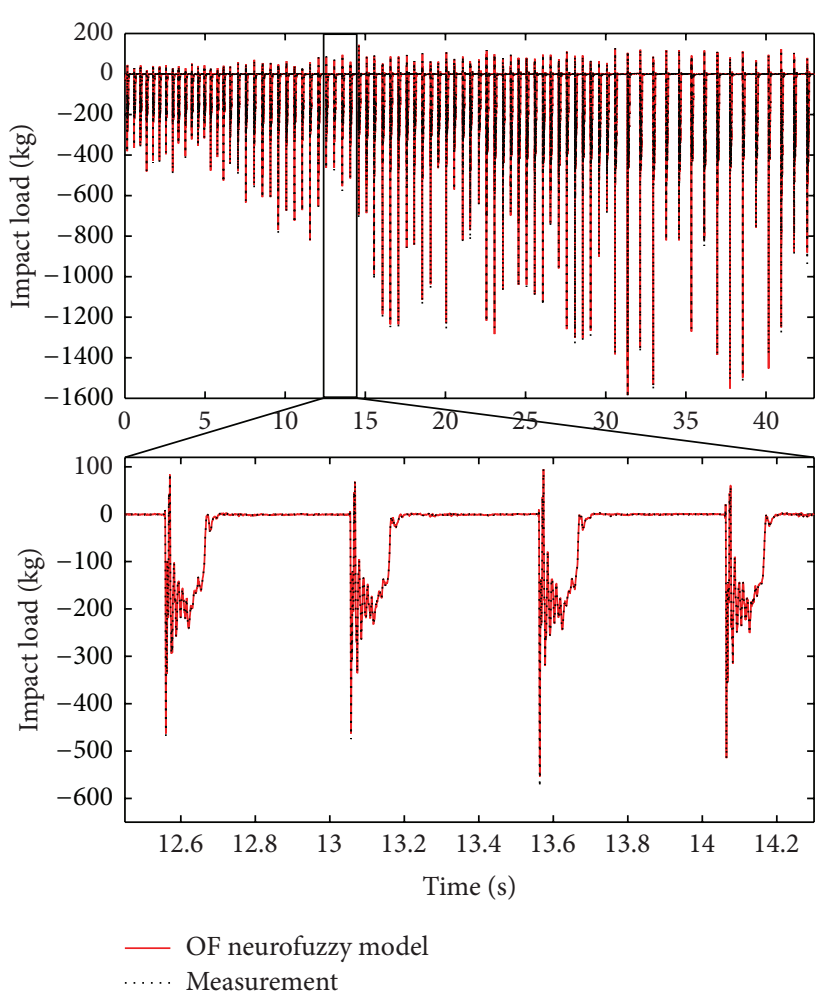

FIGURE 20: Validation.
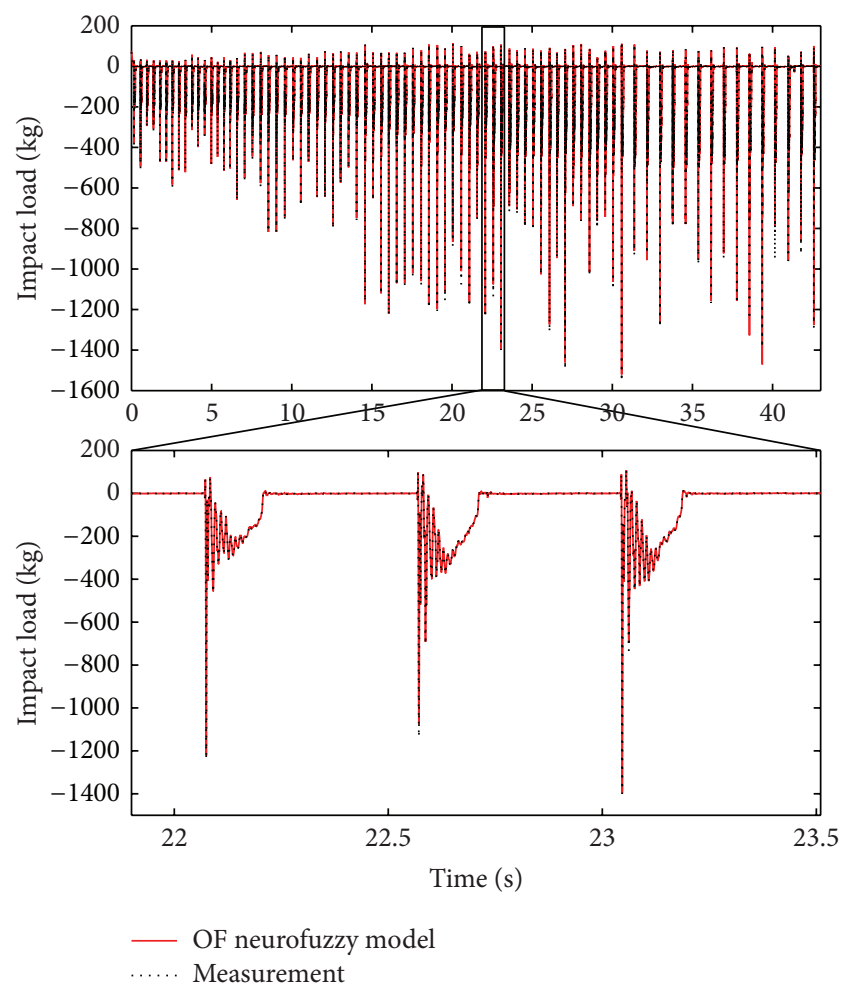

Figure 21: Test.

where var represents the variance of data. The fitting rate of index $J_{4}$ shows the accuracy of the predictions of the models. 

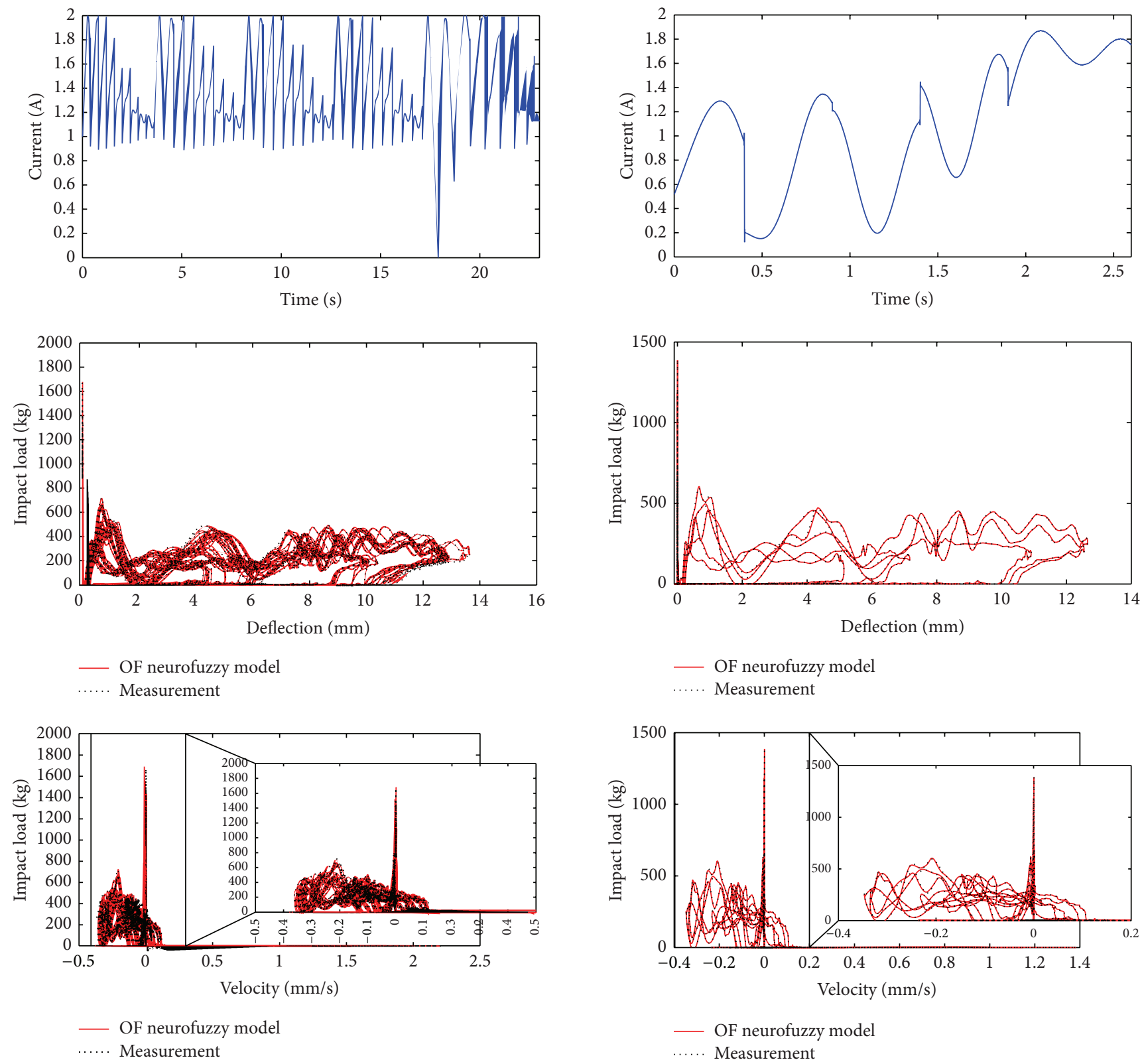

FIGURE 22: Impact load-displacement and impact load-velocity curves: different drop release heights and sinusoidal current signal.

The better the trained model predicts the measurement results accurately, the more the fitting rate of index $J_{4}$ will become close to 100 .

Table 7 shows the results of the error analysis between the trained and actual data for the different SI approaches.

It is observed from training, validation, and testing processes that the fuzzy models achieved a great performance. But the performance of the OF neurofuzzy model, in terms of accuracy and peak impact load predictions, is better than the conventional neurofuzzy model. The accuracy of the OF neurofuzzy model is about $99 \%$ for training, validation, and testing in terms of the evaluation index $J_{4}$, which means that the OF neurofuzzy is very effective in predicting the dynamic

Figure 23: Impact load-displacement and impact load-velocity curves: different drop release heights and random current signal.

responses of the MR damper under high impact loads. It is also found that $J_{1}, J_{2}$, and $J_{3}$ of the OF neurofuzzy model are better than those of the benchmark models. For example, in the training of the OF neurofuzzy model, the maximum difference between the estimate and the measurement is $131.55 \mathrm{~kg}$, which is $8 \%$ of the measurement $(1557.6 \mathrm{~kg})$ for the trained model.

\section{Conclusion}

Various parametric and nonparametric SI approaches for estimating the nonlinear impact response of MR dampers under a variety of high impact loadings and current signals are studied in this paper. The Bingham, Bouc-Wen, and two 

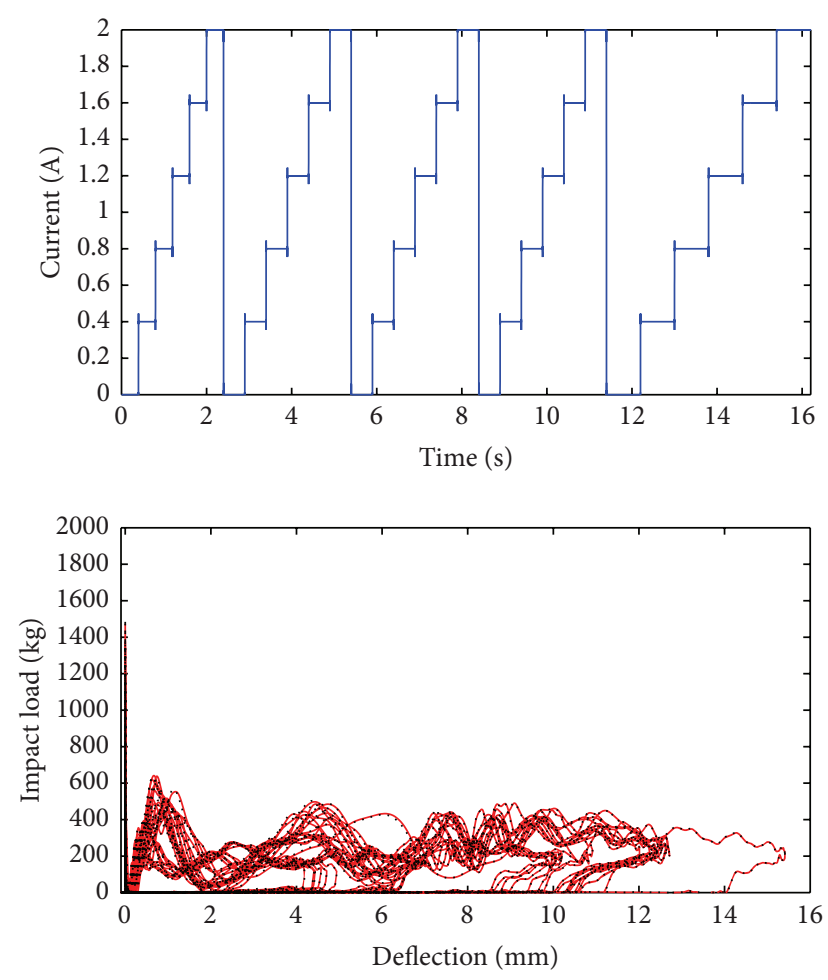

— OF neurofuzzy model ..... Measurement

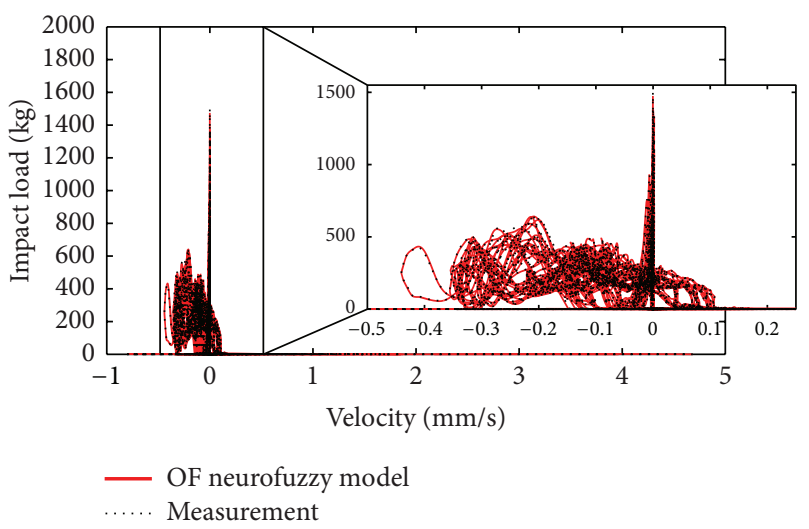

FIGURE 24: Impact load-displacement and impact load-velocity curves: different drop release heights and constant current signal.

Takagi-Sugeno fuzzy models are investigated. To obtain the input-output data set, a series of experimental studies are performed. The MR damper fluids are controlled with constant, sinusoidal, and random currents under different impact loads. A large number of drop release testing is performed three times to train, validate, and test the models. In the training of the fuzzy models, the deflection, acceleration, velocity, and current signals are used as input signals to predict the applied high impact force of the MR damper. Various inputoutput data combinations with different types of membership function (MF) are considered in this study. It is confirmed from the extensive testing and modeling that the appropriate selections of current levels, the training data set, and the MF types are very important in improving the performance of the neurofuzzy models. Although the benchmark parametric models were effective in estimating the behavior of MR dampers when the velocity of the applied forces is low and/or the applied currents are constant, they do not produce the reasonable match for random current signals under a variety of high impact loads. The conventional neurofuzzy model gives reasonable match between the predicted and actual test data. However the peak impact value predictions, which is essential in design of a control system to dissipate the impact energy, is not accurate. In conclusion, it is demonstrated from both the training and validation and testing results that the OF neurofuzzy model is very effective in modeling the nonlinear behaviors of an MR damper employing random current signals under a variety of high impact loads.

\section{Conflict of Interests}

The authors declare that there is no conflict of interests regarding the publication of this paper.

\section{Acknowledgments}

This research was supported by the MSIP (Ministry of Science, ICT \& Future Planning), Korea, under the C- ITRC (Convergence Information Technology Research Center) Support Program (NIPA-2014-H0401-14-1022) supervised by the NIPA (National IT Industry Promotion Agency).

\section{References}

[1] J. Wang and Y. Li, "Dynamic simulation and test verification of MR shock absorber under impact load," Journal of Intelligent Material Systems and Structures, vol. 17, no. 4, pp. 309-314, 2006.

[2] M. Ahmadian and J. A. Norris, "Experimental analysis of magnetorheological dampers when subjected to impact and shock loading," Communications in Nonlinear Science and Numerical Simulation, vol. 13, no. 9, pp. 1978-1985, 2008.

[3] H. Hongsheng, Q. Suxiang, W. Jiong, and L. Zhaochun, "Performance simulation and experimental evaluation for a magnetrheological damper under impact load," in Proceedings of the IEEE International Conference on Robotics and Biomimetics (ROBIO '08), pp. 1538-1543, Bangkok, Thailand, February 2009.

[4] M. Wiklo and J. Holnicki-Szulc, "Optimal design of adaptive structures: part I. Remodeling for impact reception," Structural and Multidisciplinary Optimization, vol. 37, no. 3, pp. 305-318, 2009.

[5] M. Wiklo and J. Holnicki-Szulc, "Optimal design of adaptive structures. Part II. Adaptation to impact loads," Structural and Multidisciplinary Optimization, vol. 37, no. 4, pp. 351-366, 2009.

[6] G. R. Consolazio, M. T. Davidson, and D. J. Getter, "Vessel crushing and structural collapse relationships for bridge design," Structures Research Report, Department of Civil and Coastal Engineering, University of Florida, 2010.

[7] K. S. Arsava, Y. Kim, T. El-Korchi, and H. S. Park, "Nonlinear system identification of smart structures under high impact loads," Smart Materials and Structures, vol. 22, no. 5, Article ID 055008, 2013. 
[8] K. S. Arsava, Y. Nam, and Y. Kim, "Nonlinear system identification of smart reinforced concrete structures under impact loads," Journal of Vibration and Control, 2015.

[9] R. Mitchell, Y. J. Cha, Y. Kim, and A. Mahajan, "Active control of highway bridges subject to a variety of earthquake loads," Earthquake Engineering and Engineering Vibration. In press.

[10] R. Mitchell, Y. Kim, T. El-Korchi, and Y.-J. Cha, "Wavelet-neurofuzzy control of hybrid building-active tuned mass damper system under seismic excitations," Journal of Vibration and Control, vol. 19, no. 12, pp. 1881-1894, 2013.

[11] Y. Kim, R. Langari, and S. Hurlebaus, "Model-based multiinput, multi-output supervisory semiactive nonlinear fuzzy controller," Computer-Aided Civil and Infrastructure Engineering, vol. 25, no. 5, pp. 387-393, 2010.

[12] Y. Kim, S. Hurlebaus, and R. Langari, "Fuzzy control of large civil structures subjected to natural hazards," in Recent Advances in Intelligent Control Systems, W. Yu, Ed., pp. 3-20, Springer, London, UK, 2009.

[13] B. F. Spencer Jr., S. J. Dyke, M. K. Sain, and J. D. Carlson, "Phenomenological model for magnetorheological dampers," Journal of Engineering Mechanics, vol. 123, no. 3, pp. 230-238, 1997.

[14] P. J. Lynch, Decentralization of wireless monitoring and control technologies for smart civil structures [Dissertation], Department of Civil and Environmental Engineering and the Committee on Graduate Studies of Stanford University, Stanford, Calif, USA, 2002.

[15] Y. Kim, R. Langari, and S. Hurlebaus, "Semiactive nonlinear control of a building with a magnetorheological damper system," Mechanical Systems and Signal Processing, vol. 23, no. 2, pp. 300-315, 2009.

[16] R. Mitchell, Y. Kim, and T. El-Korchi, "System identification of smart structures using a wavelet neuro-fuzzy model," Smart Materials and Structures, vol. 21, no. 11, Article ID 115009, 2012.

[17] S.-G. Luca, F. Chira, and V.-O. Rosca, "Passive, active and semi-active control systems in civil engineering," Bulletin of the Polytechnic Institute of Jassy, Constructions, Architecture Section, vol. 3, pp. 23-31, 2005.

[18] J. Scruggs, Active, regenerative control of civil structures [M.S. thesis], Department of Electrical and Computer Engineering, Faculty of the Virginia Polytechnic Institute and State University, Blacksburg, Va, USA, 1999.

[19] J. Scruggs and D. Lindner, "Active energy control in civil structures," in Smart Structures and Materials: Smart Systems for Bridges, Structures, and Highways, vol. 3671 of Proceedings of SPIE, pp. 194-205, Newport Beach, Calif, USA, March 1999.

[20] R. Sharifi, Y. Kim, and R. Langari, "Sensor fault isolation and detection of smart structures," Smart Materials and Structures, vol. 19, no. 10, Article ID 105001, 2010.

[21] Y. Kim, J. W. Bai, and L. D. Albano, "Fragility estimates of smart structures with sensor faults," Journal of Smart Materials and Structures, vol. 22, no. 12, Article ID 125012, 2014.

[22] Y. Kim, C. Kim, and R. Langari, "Novel bio-inspired smart control for hazard mitigation of civil structures," Smart Materials and Structures, vol. 19, no. 11, Article ID 115009, 2010.

[23] S. Hurlebaus and L. Gaul, "Smart structure dynamics," Mechanical Systems and Signal Processing, vol. 20, no. 2, pp. 255-281, 2006.

[24] S. J. Dyke and B. F. Spencer Jr., "Seismic response control using multiple MR dampers," in Proceedings of the 2nd International Workshop on Structural Control, vol. 2, pp. 163-173, Hong Kong, December 1996.
[25] S. J. Dyke, B. F. Spencer Jr., M. K. Sain, and J. D. Carlson, "An experimental study of MR dampers for seismic protection," Smart Materials and Structures, vol. 7, no. 5, pp. 693-703, 1998.

[26] S. J. Dyke, F. Yi, J. M. Caicedo, and J. D. Carlson, "Experimental verification of multiinput seismic control strategies for smart dampers," Journal of Engineering Mechanics, vol. 127, no. 11, pp. 1152-1164, 2001.

[27] F. Yi, S. J. Dyke, S. Frech, and J. D. Carlson, "Investigation of magnetorheological dampers for earthquake hazard mitigation," in Proceedings of the 2nd World Conference on Structural Control, vol. 2, pp. 349-358, Kyoto, Japan, June-July 1998.

[28] F. Yi, S. J. Dyke, J. M. Caicedo, and J. D. Carlson, "Seismic response control using smart dampers," in Proceedings of the 1999 American Control Conference (ACC '99), pp. 1022-1026, San Diego, Calif, USA, June 1999.

[29] Y. Kim, R. Langari, and S. Hurlebaus, "Control of a seismically excited benchmark building using linear matrix inequalitybased semiactive nonlinear fuzzy control," ASCE Journal of Structural Engineering, vol. 136, no. 8, pp. 1023-1026, 2010.

[30] K. C. Schurter and P. N. Roschke, "Fuzzy modeling of a magnetorheological damper using ANFIS," in Proceedings of the 9th IEEE International Conference on Fuzzy Systems (FUZZIEEE '00), vol. 1, pp. 122-127, IEEE, San Antonio, Tex, USA, May 2000.

[31] K. Bani-Hani, J. Ghaboussi, and S. P. Schneider, "Experimental study of identification and control of structures using neural network, part 1: identification," Earthquake Engineering \& Structural Dynamics, vol. 28, no. 9, pp. 995-1018, 1999.

[32] J. W. Lin, R. Betti, A. W. Smyth, and R. W. Longman, "On-line identification of non-linear hysteretic structural systems using a variable trace approach," Earthquake Engineering and Structural Dynamics, vol. 30, no. 9, pp. 1279-1303, 2001.

[33] Y. Kim and R. Langari, "Nonlinear identification and control of a building structure with a magnetorheological damper," in Proceedings of the American Control Conference (ACC '07), pp. 3353-3358, New York, NY, USA, July 2007.

[34] F. Kerber, S. Hurlebaus, B. M. Beadle, and U. Stöbener, "Control concepts for an active vibration isolation system," Mechanical Systems and Signal Processing, vol. 21, no. 8, pp. 3042-3059, 2007.

[35] Y. Kim, R. Langari, and S. Hurlebaus, "MIMO fuzzy identification of building-MR damper system," International Journal of Intelligent \& Fuzzy Systems, vol. 22, no. 4, pp. 185-205, 2011.

[36] Y. Kim, Y. H. Kim, and S. Lee, "Multivariable nonlinear identification of smart buildings," Mechanical Systems and Signal Processing. In press.

[37] K. Suresh, S. K. Deb, and A. Dutta, "Parametric system identification of multistoreyed buildings with non-uniform mass and stiffness distribution," in Proceedings of the 14th World Conference of Earthquake Engineering (WCEE '08), Paper ID: 05-01-0053, Beijing, China, October 2008.

[38] Y. Kim, S. S. Shin, and J. D. Plummer, "A wavelet-based autoregressive fuzzy model for forecasting algal blooms," Environmental Modelling \& Software, vol. 62, pp. 1-10, 2014.

[39] Y. Kim, K. H. Kim, and B.-S. Shin, "Fuzzy model forecasting of offshore bar-shape profiles under high waves," Expert Systems with Applications, vol. 41, no. 13, pp. 5771-5779, 2014.

[40] S.-L. Hung, C. S. Huang, C. M. Wen, and Y. C. Hsu, "Nonparametric identification of a building structure from experimental data using wavelet neural network," Computer-Aided Civil and Infrastructure Engineering, vol. 18, no. 5, pp. 356-368, 2003. 
[41] J.-W. Lin and R. Betti, "On-line identification and damage detection in non-linear structural systems using a variable forgetting factor approach," Earthquake Engineering and Structural Dynamics, vol. 33, no. 4, pp. 419-444, 2004.

[42] J. N. Yang and S. Lin, "On-line identification of non-linear hysteretic structures using an adaptive tracking technique," International Journal of Non-Linear Mechanics, vol. 39, no. 9, pp. 1481-1491, 2004.

[43] D.-Y. Lee, Y.-T. Choi, and N. M. Wereley, "Performance analysis of ER/MR impact damper systems using herschel-bulkley model," Journal of Intelligent Material Systems and Structures, vol. 13, no. 7-8, pp. 525-531, 2002.

[44] H. Xiang, Q. Fang, Z. Gong, and H. Wu, "Experimental investigation into magnetorheological damper subjected to impact loads," Transactions of Tianjin University, vol. 14, pp. 540-544, 2008.

[45] H. A. Smith and J. G. Chase, "Identification of structural system parameters using the Cascade-Correlation neural network," Journal of Dynamic Systems, Measurement and Control, Transactions of the ASME, vol. 116, no. 4, pp. 790-792, 1994.

[46] S. Tesfamariam and H. Najjaran, "Adaptive network-fuzzy inferencing to estimate concrete strength using mix design," Journal of Materials in Civil Engineering, vol. 19, no. 7, pp. 550560, 2007.

[47] L. Faravelli and T. Yao, "Use of adaptive networks in fuzzy control of civil structures," Computer-Aided Civil and Infrastructure Engineering, vol. 11, no. 1, pp. 67-76, 1996.

[48] E. T. Fonseca, P. C. G. D. S. Vellasco, M. M. B. R. Vellasco, and S. A. L. de Andrade, "A neuro-fuzzy evaluation of steel beams patch load behaviour," Advances in Engineering Software, vol. 39, no. 7, pp. 558-572, 2008.

[49] S. Zadeh, Y. Kim, and J. Ahn, "PCA-based neuro-fuzzy model for system identification of smart structures," Smart Structures and Systems, vol. 15, no. 5, 2015.

[50] Y. Kim, R. Mallick, S. Bhowmick, and B.-L. Chen, "Nonlinear system identification of large-scale smart pavement systems," Expert Systems with Applications, vol. 40, no. 9, pp. 3551-3560, 2013.

[51] M. Muzzammil, "ANFIS approach to the scour depth prediction at a bridge abutment," Journal of Hydroinformatics, vol. 12, no. 4, pp. 474-485, 2010.

[52] U. J. Na, T. W. Park, M. Q. Feng, and L. Chung, "Neuro-fuzzy application for concrete strength prediction using combined non-destructive tests," Magazine of Concrete Research, vol. 61, no. 4, pp. 245-256, 2009.

[53] V. Balasubramaniam, P. N. Raghunath, and K. Suguna, "An adaptive neuro-fuzzy inference system based modeling for corrosion-damaged reinforced HSC beams strengthened with external glass fibre reinforced polymer laminates," Journal of Computer Science, vol. 8, no. 6, pp. 879-890, 2012.

[54] H. Wang, "Modeling of magnetorheological damper using neuro-fuzzy system," in Fuzzy Information and Engineering Volume 2, vol. 62 of Advances in Intelligent and Soft Computing, pp. 1157-1164, Springer, Berlin, Germany, 2009.

[55] H. Wang and X. Shi, "Hierarchical ANFIS identification of magneto-rheological dampers," Applied Mechanics and Materials, vol. 29-32, pp. 343-348, 2010.

[56] H. Wang and H. Hu, "The neuro-fuzzy identification of MR damper," in Proceedings of the 6th International Conference on Fuzzy Systems and Knowledge Discovery (FSKD '09), pp. 464468, chn, August 2009.
[57] M. Zeinali, S. A. Mazlan, A. Y. Abd Fatah, and H. Zamzuri, "A phenomenological dynamic model of a magnetorheological damper using a neuro-fuzzy system," Smart Materials and Structures, vol. 22, no. 12, Article ID 125013, 2013.

[58] K. Sekuła, C. Graczykowski, and J. Holnicki-Szulc, "On-line impact load identification," Shock and Vibration, vol. 20, no. 1, pp. 123-141, 2013.

[59] M. Gencoglu and B. Mobasher, "Static and impact behavior of fabric reinforced cement composites in flexure," in High Performance Fiber Reinforced Cement Composites-HPFRCC5, vol. 53, pp. 463-470, Springer, Mainz, Germany, 2007.

[60] G. R. Consolazio, R. A. Cook, and M. C. McVay, "Barge impact testing of the St. George Island Causeway bridge phase III: physical testing and data interpretation," Structures Research Report, Department of Civil and Coastal Engineering, University of Florida, 2006.

[61] G. R. Consolazio and M. C. McVay, "Development of improved bridge design provisions for barge impact loading," Structures Research Report, Department of Civil and Coastal Engineering, University of Florida, Gainesville, Fla, USA, 2008.

[62] D. H. Wang and W. H. Liao, "Magnetorheological fluid dampers: a review of parametric modelling," Smart Materials and Structures, vol. 20, no. 2, Article ID 023001, 2011.

[63] A. Dominguez, R. Sedaghati, and I. Stiharu, "Modelling the hysteresis phenomenon of magnetorheological dampers," Smart Materials and Structures, vol. 13, no. 6, pp. 1351-1361, 2004.

[64] A. Dominguez, R. Sedaghati, and I. Stiharu, "A new dynamic hysteresis model for magnetorheological dampers," Smart Materials and Structures, vol. 15, no. 5, pp. 1179-1189, 2006.

[65] L. Fu, L.-P. Lin, and X.-H. Xu, "Research on modeling and fuzzy control of magneto-rheological intelligent buffer system for impact load," Journal of Shanghai Jiaotong University (Science), vol. 17, no. 5, pp. 567-572, 2012.

[66] P. Tahmasebi and A. Hezarkhani, "Application of adaptive neuro-fuzzy inference system for grade estimation; case study, sarcheshmeh porphyry copper deposit, Kerman, Iran," Australian Journal of Basic and Applied Sciences, vol. 4, no. 3, pp. 408-420, 2010.

[67] J.-S. R. Jang, "ANFIS: adaptive-network-based fuzzy inference system," IEEE Transactions on Systems, Man and Cybernetics, vol. 23, no. 3, pp. 665-685, 1993.

[68] J. S. R. Jang, C. T. Sun, and E. Mizutani, Neuro-Fuzzy and Soft Computing: A Computational Approach to Learning and Machine Intelligence, Prentice Hall, Upper Saddle River, NJ, USA, 1997.

[69] H. Adeli and X. Jiang, "Dynamic fuzzy wavelet neural network model for structural system identification," Journal of Structural Engineering, vol. 132, no. 1, pp. 102-111, 2006.

[70] G. M. Mikułowski and J. Holnicki-Szulc, "Adaptive landing gear concept-feedback control validation," Smart Materials and Structures, vol. 16, no. 6, pp. 2146-2158, 2007. 

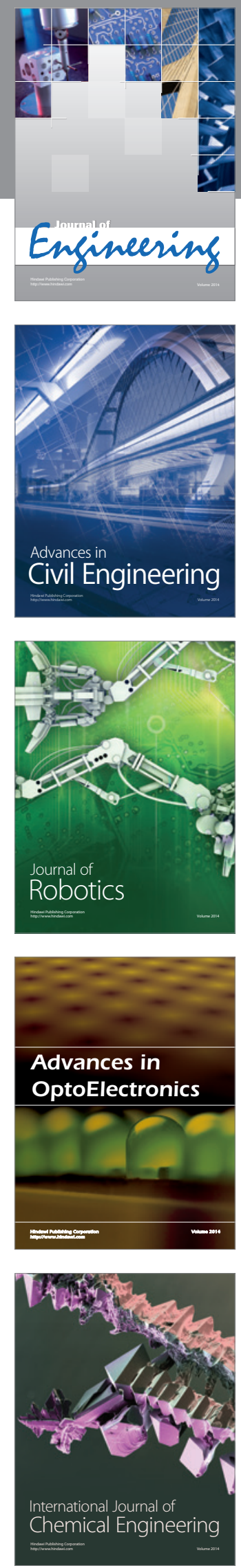

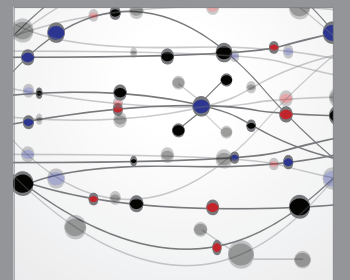

The Scientific World Journal
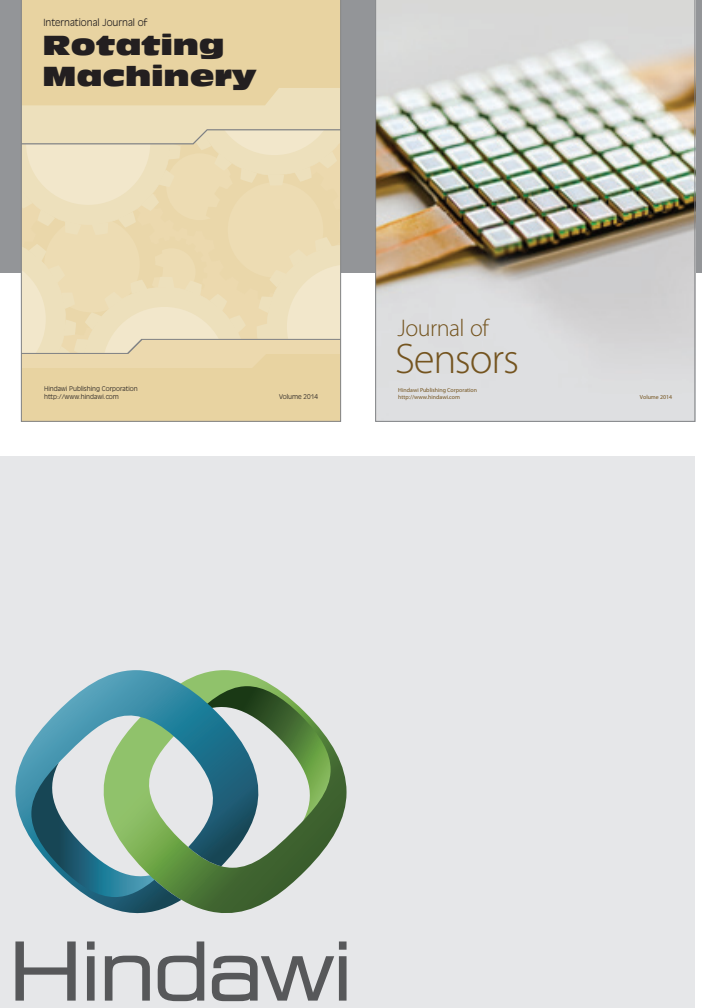

Submit your manuscripts at http://www.hindawi.com
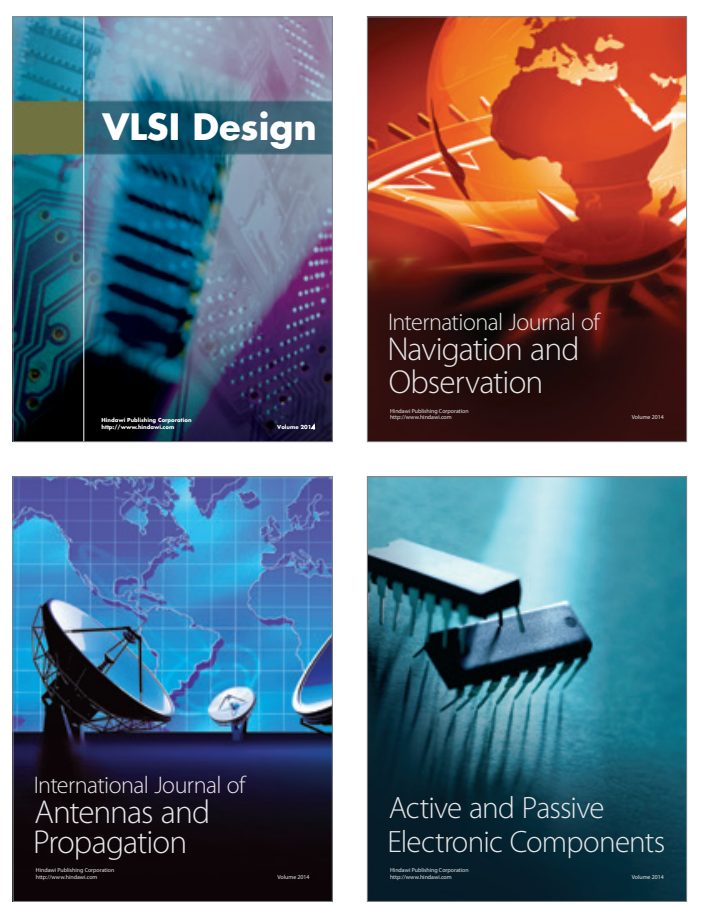
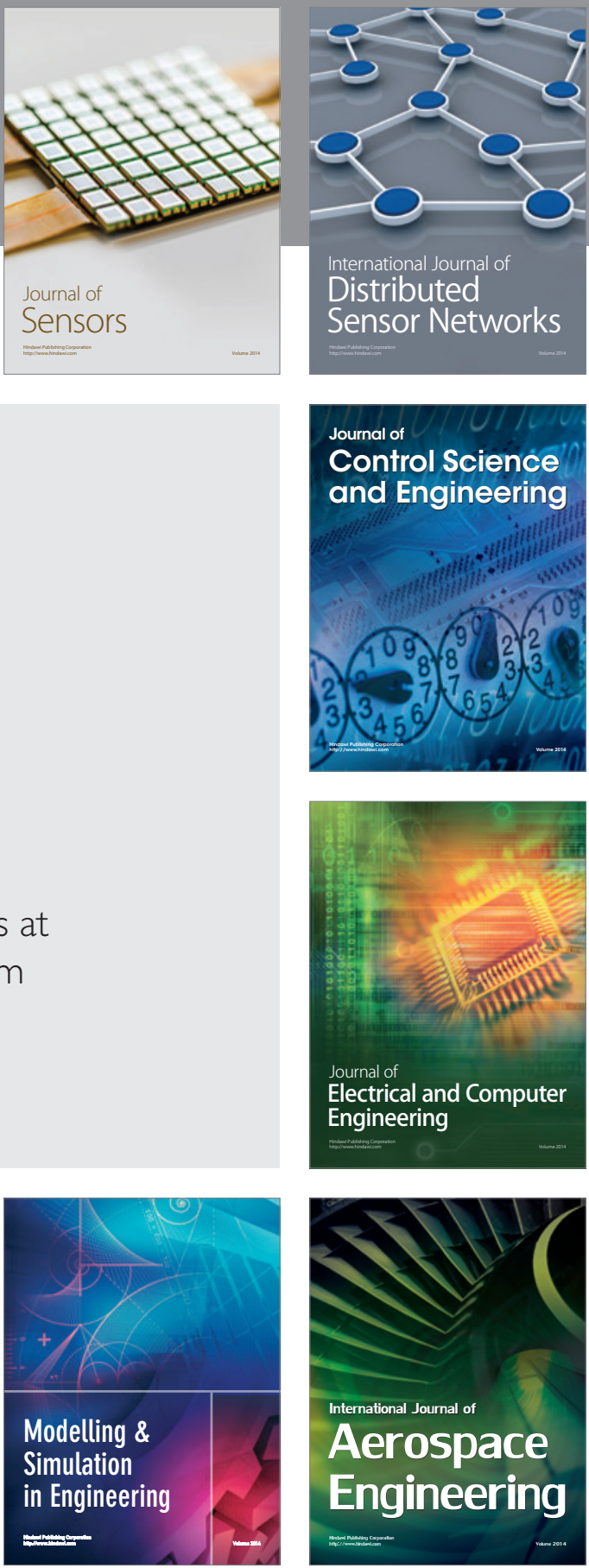

Journal of

Control Science

and Engineering
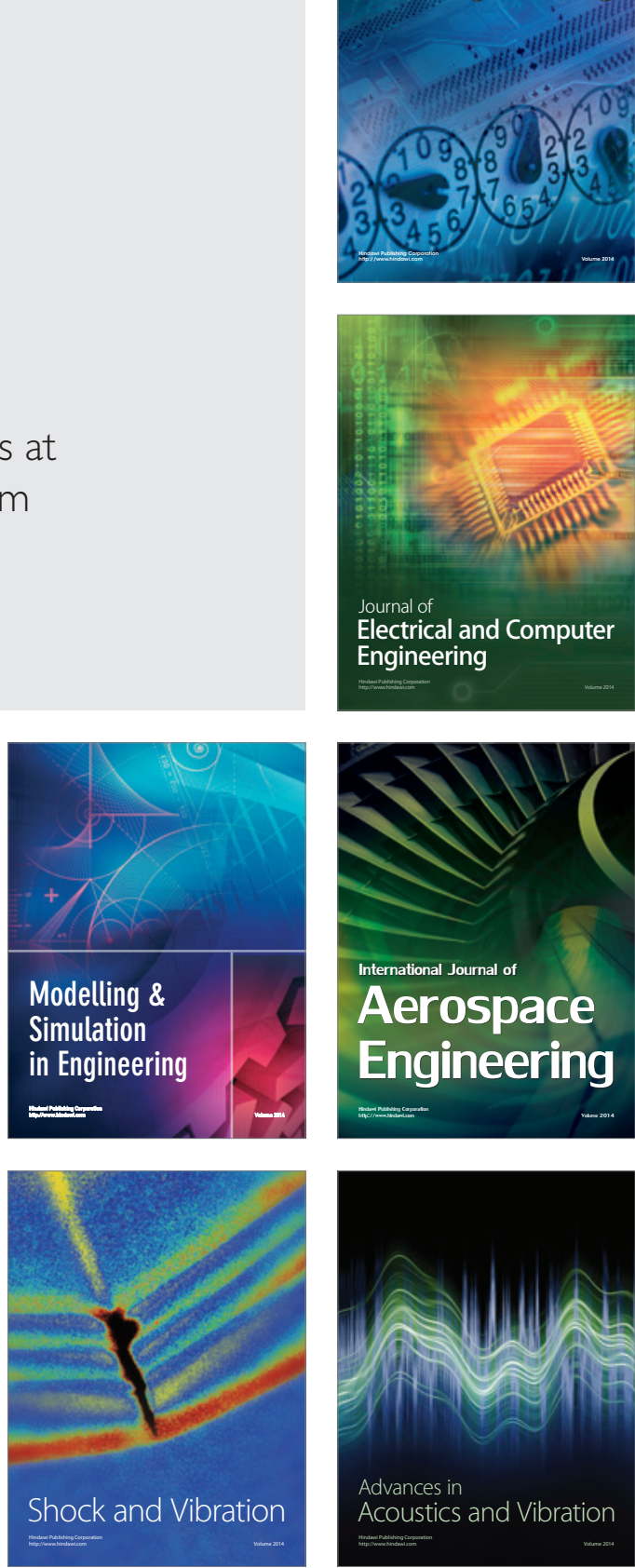